\title{
A Simplified Approach for Designing SRMs in Composite Continuous Twin-Tub Girder Bridges
}



Robert J. Connor, Cem Korkmaz, Leslie E. Campbell,

Francisco J. Bonachera Martín, Jason B. Lloyd

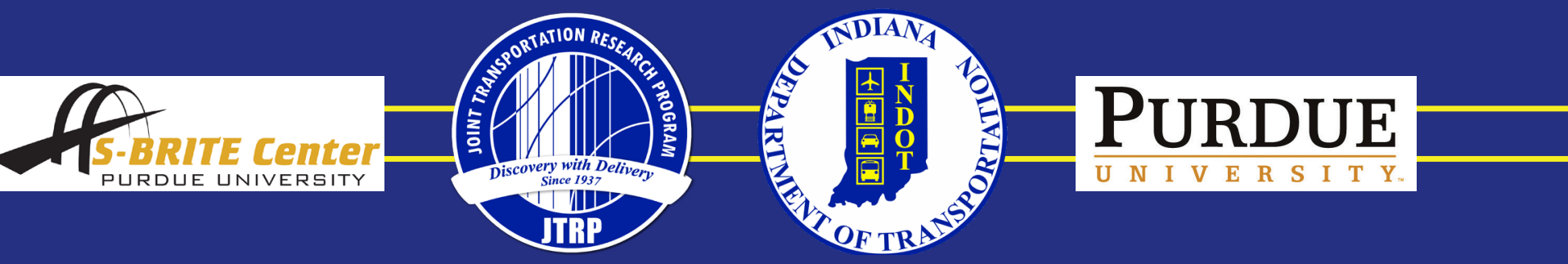




\section{RECOMMENDED CITATION}

Connor, R. J., Korkmaz, C., Campbell, L. E., Bonachera Martín, F. J., \& Lloyd, J. (2020). A simplified approach for designing SRMs in composite continuous twin-tub girder bridges. West Lafayette, IN: Purdue University. https://doi.org/10.5703/1288284317106

\section{AUTHORS}

Jason B. Lloyd

American Institute of Steel Construction

Leslie E. Campbell

U.S. Army Corps of Engineerings

Francisco Javier Bonachera Martín

Michael Baker International

Robert J. Connor

Purdue University

\section{NOTICE}

The contents of this document reflect the views of the authors, who are responsible for the facts and the accuracy of the data presented herein. The report does not constitute a standard, specification or regulation. 


\section{EXECUTIVE SUMMARY}

High torsional rigidity and attractive aesthetics in construction of twin-tub girder bridges make them preferable for the design of curved bridges. However, according to the concepts associated with the term "Fracture Critical (FC)" that are in place today, all two-girder bridges are classified as having FC members (FCMs) due to their perceived lack of load path redundancy. For a steel bridge with FCMs, the fracture of any of the FCMs is assumed to result in complete catastrophic failure or significant loss of serviceability; hence, every two years twin-tub girder bridges undergo very expensive hands-on field inspections.

Recent works performed by Purdue University researchersincluding NCHRP Project 12-87a (Connor et al., 2018) reported in NCHRP Report 883 Fracture-Critical System Analysis for Steel Bridges (Connor et al., 2018), Ramp TH over Interstate $43 / 894$ in Milwaukee (Connor \& Korkmaz, 2016), and Analytical Evaluation of the Post-fracture System Performance of Typical Steel Twin-Tub Girder Bridges in the State of Wisconsin Phase I (Korkmaz et al., 2018)-showed that twin-tub girder bridges often possess significant reserve capacity even when one girder is completely severed. The bridges were evaluated using the system analysis procedures defined in the AASHTO Guide Specifications for Analysis and Identification of Fracture Critical Members and System Redundant Members (AASHTO, 2018). A reliability-based approach was used, and all load combinations were in accordance with the AASHTO Guide Specifications (AASHTO, 2018). In the first phase of the research completed for the Wisconsin DOT (Korkmaz et al., 2018), 18 multi-span twin-tub girder bridge units (in total 2.4 miles, 70 spans) were analyzed to determine if the steel tub girders could be classified as System Redundant Members (SRMs). Full 3D non-linear dynamic finite element analysis (FEA) was required to complete the evaluations. The results from Phase I demonstrated that all bridges analyzed in the project possess considerable reserve strength in the faulted state and that the steel tub girders do not meet the definition of having a fracture critical member. It is important to note that all of the twin-tub girder bridges analyzed in Phase I (Korkmaz et al., 2018) have multiple full-depth and full-width intermediate diaphragms and continuous spans. These features provide additional load paths and help to make the bridges redundant, thereby avoiding many failure modes which simple span bridges and continuous bridges without full-depth and full-width intermediate diaphragms are likely to experience.

To avoid the need for complex FEA, it would be advantageous to have a simple guideline that could be used during the design of future twin-tub girder bridges. These guidelines would ensure that these bridges would satisfy the loading requirements and failure criteria included in the AASHTO Guide Specifications (AASHTO, 2018). However, no such guidelines currently exist for designers. By simply meeting AASHTO LRFD (AASHTO, 2020) Strength I requirements in the unfaulted state during design, there are no assurances that the bridge would meet the AASHTO Guide Specifications (AASHTO, 2018) requirements.

This report presents a simplified approach to ensure newly designed twin-tub girder bridges will meet all the requirements defined in the AASHTO Guide Specifications (AASHTO, 2018) without performing in-depth FEA. In brief, this report explains the following:

1. The geometric limitations and configurations to which the proposed criteria apply.

2. How to design and detail such bridges in order to meet the criteria and satisfy minimum strength and serviceability performance requirements to avoid expected failure modes.

AASHTO-ready proposed specifications are included in Appendix A. Proposed Specifications. It is anticipated that these provisions could be incorporated into the AASHTO LRFD BDS as a new article 6.6.3 Special Provisions for Twin Tub Girder Bridges. An example of how to use the provisions is demonstrated in Appendix B. Design Example. 


\section{CONTENTS}

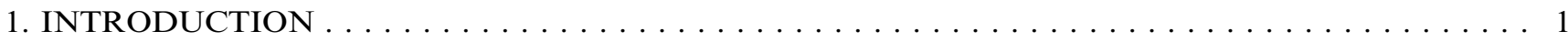

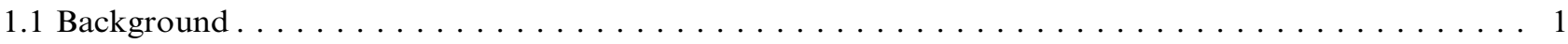

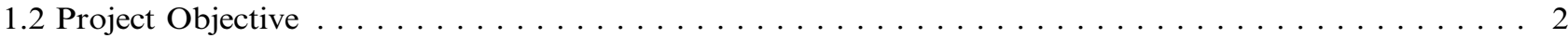

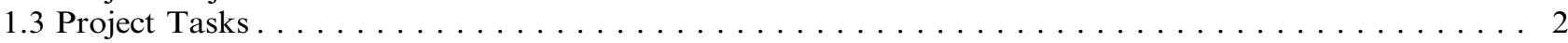

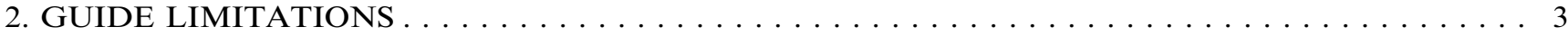

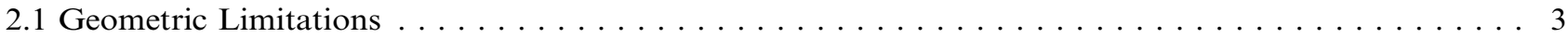

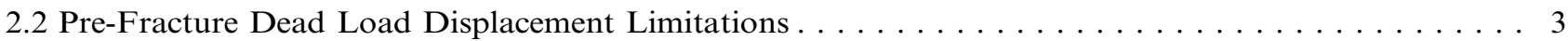

2.3 Bridges Not Within the Limitations . . . . . . . . . . . . . . . . . . . . .

3. PROPOSED GUIDANCE FOR DESIGNING SRMS IN TWIN-TUB GIRDER BRIDGES . . . . . . 5

3.1 Stud Pull-Out Failure (Haunch Separation) $\ldots \ldots \ldots \ldots$

3.2 Intermediate Diaphragm Web Shear and Flexural Yielding . . . . . . . . . . . . . . . 7

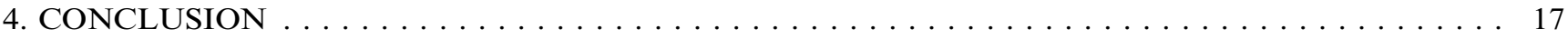

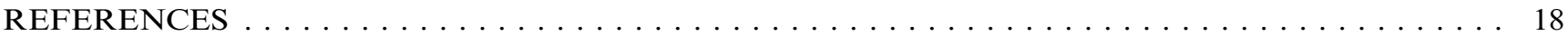

APPENDICES

Appendix A. Proposed Specifications for Designing SRMs in Composite Continuous

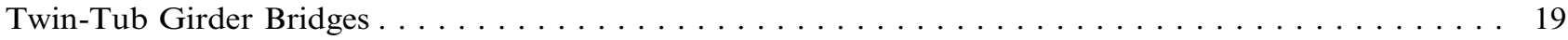

Appendix B. Design Example . . . . . . . . . . . . . . . . . . . . . . . . . . . . . 19 


\section{LIST OF TABLES}

Table

Table 1.1 List of the bridges with FC members where fractures have been observed in main members

Table 2.1 The details of 18 bridge units for WisDOT used in the parametric study

Table 2.2 Dead load displacement vs. inelasticity

Table 3.1 Shear stud properties of WisDOT bridges

Table 3.2 WisDOT bridges girder top flanges vs. diaphragm top flanges

Table 3.3 WisDOT bridges exterior spans' bottom flange section demand/capacity ratios

Table 3.4 WisDOT bridges flexural moment in tension demand/capacity ratios

Table 3.5 WisDOT web shear demand/capacity ratios

Table 3.6 WisDOT deck torsional shear demand/capacity ratios and transverse reinforcement details

Table 3.7 Stiffness ratio between deck and intermediate diaphragms for WisDOT bridges

Table 3.8 WisDOT support bearing demand/strength

Table 3.9 WisDOT maximum horizontal support displacement

Table 3.10 WisDOT maximum vertical displacement under unfactored dead load in fractured exterior span 


\section{LIST OF FIGURES}

Figures

Page

Figure 3.1 Total moment change considering different diaphragm locations—L/8 increments

Figure 3.2 Post-fracture moment in the girders considering different diaphragm locations - $\mathrm{L} / 8$ increments

Figure 3.3 Fractured girder local bottom flange buckling next to pier in fractured span

Figure 3.4 Fractured girder thinner section local bottom flange buckling at the section change in fractured span

Figure 3.5 Web shear failure in a simple span bridge 


\section{INTRODUCTION}

\subsection{Background}

The concepts associated with the term Fracture Critical (FC) that are in place today were developed in the mid-1970s when shop fabrication and inspection, fatigue design, detailing practices, material toughness, and analytical tools were very different. These processes have evolved and improved substantially over the past 30 to 40 years. The bridges built today present a much lower risk of fracture compared to those built prior to about 1980 due to enhanced quality standards for FC member fabrication and shop inspection. In addition, there have been significant advancements in the areas of fatigue design and detailing to prevent in-plane fatigue and to address distortion cracking issues.

Interestingly, there is little evidence that FC in-service inspection contributes significantly to the improved overall reliability of modern bridges (Connor et al., 2005). FC inspection practices were initiated to help identify fatigue cracking that was prevalent in older bridges. Once initiated, fatigue cracks often continue to grow larger until they present a brittle fracture risk. The rationale for FC in-service inspection was to ensure these cracks were found at an early stage, i.e., before they present a fracture risk. This needs to be critically re-evaluated for modern structures as contemporary fatigue design practice has greatly reduced the probability of fatigue cracking in most structures. Therefore, it is logical that new FC bridges have less need for in-depth inspection as compared to older FC bridges.
Further, the maximum allowable interval between FC inspections (i.e., 24 months) specified in the Code of Federal Regulations (CFRs) (Inspection Frequency, 2013) was not developed using any quantitative engineering-based criteria. Rather, it was based on the perception that this was the "right" interval. Nevertheless, concerns remain regarding the performance of bridges classified as having FCMs if one of the two primary load carrying members should completely fracture.

There are a number of case studies reported in the literature where full-depth fractures have been observed in multiple bridges made of two I-girders, as shown in Table 1.1. Even though after-fracture system performance was not a consideration in design for any of these bridges, in all cases the bridges remained standing, and in most cases, continued to carry service loads (see Table 1.1). Thus, in all cases, the bridges, several of which were non-composite, were capable of redistributing loads through system performance.

Similar to I-girder bridges, recent work performed by Purdue University researchers including NCHRP Project 12-87a (Connor et al., 2018) reported in NCHRP Report 883 Fracture-Critical System Analysis for Steel Bridges (Connor et al., 2018), Ramp TH over Interstate 43/894 in Milwaukee (Connor \& Korkmaz, 2016), and Analytical Evaluation of the Post-fracture System Performance of Typical Steel Twin-Tub Girder Bridges in the State of Wisconsin Phase I (Korkmaz et al., 2018) showed that twin-tub girder bridges often possess significant reserve capacity even when one girder is completely severed. The bridges were evaluated using

TABLE 1.1

List of the bridges with FC members where fractures have been observed in main members

\begin{tabular}{|c|c|c|c|c|}
\hline Bridge & Type of Failure & Structural Type & Span Length (ft.) & $\begin{array}{l}\text { Conditions After } \\
\text { Fracture }\end{array}$ \\
\hline $\begin{array}{l}\text { Lafayette St. } \\
\text { Minneapolis, MN }\end{array}$ & $\begin{array}{l}\text { Full-depth } \\
\text { I-girder fracture }\end{array}$ & $\begin{array}{l}\text { 2-Girder } \\
\text { cont. span }\end{array}$ & 362 & $\begin{array}{l}\text { Some sagging, } \\
\text { carried traffic }\end{array}$ \\
\hline $\begin{array}{l}\text { US } 422 \text { over } \\
\text { Schuylkill River, } \\
\text { Pottstown, PA }\end{array}$ & $\begin{array}{l}\text { Partial-depth } \\
\text { I-girder fracture }\end{array}$ & $\begin{array}{l}\text { 2-Girder } \\
\text { cont. span }\end{array}$ & 150 & $\begin{array}{l}\text { No perceptible } \\
\text { deflection, carried traffic }\end{array}$ \\
\hline $\begin{array}{l}\text { Neville Island } \\
\text { over Ohio River, } \\
\text { Pittsburgh, PA }\end{array}$ & $\begin{array}{l}\text { Full-depth } \\
\text { I-girder fracture }\end{array}$ & $\begin{array}{l}\text { 2-Girder } \\
\text { cont. span }\end{array}$ & 300 & $\begin{array}{l}\text { No perceptible } \\
\text { deflection, carried traffic }\end{array}$ \\
\hline $\begin{array}{l}\text { Hoan Bridge } \\
\text { Milwaukee, WI }\end{array}$ & $\begin{array}{l}\text { Multiple full-depth } \\
\text { I-girder fractures }\end{array}$ & $\begin{array}{l}\text { 3-Girder } \\
\text { cont. span }\end{array}$ & 217 & $\begin{array}{l}\text { Considerable } \\
\text { deflection, carried light } \\
\text { traffic for a brief period }\end{array}$ \\
\hline $\begin{array}{l}\text { Dan Ryan } \\
\text { Expressway } \\
\text { Chicago, IL } \\
\end{array}$ & $\begin{array}{l}\text { Full-depth box } \\
\text { girder fracture }\end{array}$ & Cross Girder & 40 & $\begin{array}{l}\text { Some deflection, } \\
\text { still carried traffic }\end{array}$ \\
\hline $\begin{array}{l}\text { Diefenbaker } \\
\text { Bridge, Prince } \\
\text { Albert, Canada }\end{array}$ & $\begin{array}{l}\text { Full-depth } \\
\text { I-girder fracture }\end{array}$ & $\begin{array}{l}\text { 2-Girder } \\
\text { cont. span }\end{array}$ & 150 & $\begin{array}{l}\text { No perceptible } \\
\text { deflection, carried traffic }\end{array}$ \\
\hline $\begin{array}{l}\text { I-40 over Rio } \\
\text { Grande, NM }\end{array}$ & $\begin{array}{l}\text { Simulated } \\
\text { full-depth } \\
\text { I-girder fracture }\end{array}$ & $\begin{array}{l}\text { 2-Girder } \\
\text { cont. span }\end{array}$ & 163 & $\begin{array}{l}\text { Testing demonstrated } \\
\text { considerable load capacity } \\
\text { after simulated fracture }\end{array}$ \\
\hline
\end{tabular}


the system analysis procedures defined in the $A A S H T O$ Guide Specifications for Analysis and Identification of Fracture Critical Members and System Redundant Members (AASHTO, 2018). A reliability-based approach was used, and all load combinations were in accordance with the AASHTO Guide Specifications (AASHTO, 2018). In the first phase of the research completed for the Wisconsin DOT (Korkmaz et al., 2018), 18 multi-span twin-tub girder bridge units (in total 2.4 miles, 70 spans) were analyzed to determine if the steel tub girders could be classified as System Redundant Members (SRMs). Full 3D non-linear dynamic finite element analysis (FEA) was required to complete the evaluations. The results of all 18 bridge units analyzed for the state of Wisconsin demonstrated that all bridges analyzed in the project possess considerable reserve strength in the faulted state and that the steel tub girders do not meet the definition of a fracture critical member. The behavior of tub girder bridges in which an individual tub is assumed to have completely fractured is presented in detail in this project. Extension of the inspection intervals or the use of a more economical inspection method may be performed for twin-tub girder bridges that are determined to be redundant (i.e., not classified as having FCMs).

\subsection{Project Objective}

To avoid the need for complex FEA to evaluate postfracture behavior, it would be advantageous to have a simplified methodology that could be used during the design of future twin-tub girder bridges. This guidance must also ensure that these bridges would satisfy the loading requirements and failure criteria included in the AASHTO Guide Specifications (AASHTO, 2018). However, no such simple guidance currently exists for designers. Further, simply by meeting AASHTO LRFD (AASHTO, 2020) Strength I requirements in the unfaulted state during design, there are no assurances that the bridge would meet the requirements of the AASHTO Guide Specifications (AASHTO, 2018).

This report presents a simplified approach to ensure newly designed twin-tub girder bridges will meet all the requirements defined in the AASHTO Guide Specifications (AASHTO, 2018) without performing in-depth FEA. In brief, this report explains the following:

1. The geometric limitations and configurations to which the proposed criteria apply.

2. How to design and detail such bridges to meet the criteria and satisfy the minimum strength and serviceability performance requirements defined in the AASHTO Guide Specifications (AASHTO, 2018).

These results of the project will be applicable not only to the state of Wisconsin, but also to the many other states which use similarly designed and detailed twin-tub structures as they would likely be classified as SRMs and not FCMs. Doing so will allow for a more rational use of limited inspection funds and increase the safety of inspectors and the public since unneeded interruptions in traffic will not be required for inspections. Proposed AASHTO ready specifications that can be directly incorporated into the AASHTO LRFD Bridge Design Specifications (AASHTO, 2020) are included in Appendix A of this report. Further, an example of how to use the provisions is included in Appendix B. Design Example.

\subsection{Project Tasks}

The primary task of this project was to develop a very simple methodology that can be used in lieu of complex non-linear FEA to determine if the girders could be classified as SRMs. If the bridge does not meet the defined criteria or follow the steps and tasks outlined in this project, it is recommended to follow the evaluation methodology contained in the $A A S H T O$ Guide Specifications (AASHTO, 2018) to evaluate the bridge redundancy to make this determination.

Specifically, the following were developed during this project:

1. Various limitations were developed to ensure future designs display similar behavior in the faulted state as the multi-span twin-tub girder bridge units analyzed for the state of Wisconsin (Korkmaz et al., 2018). Eighteen multi-span twin-tub girder bridge units (in total 2.4 miles and 70 spans) from WisDOT were used to develop the proposed simplified guidance. By studying the postfracture behavior of these bridges and understanding the common characteristics of these bridges, it was possible to develop simple criteria that if met, future twin-tub girders can be automatically classified as having SRMs without the necessity of explicitly modeling fracture in a FEA. In other words, when a bridge is designed and detailed to meet the proposed criteria, acceptable post-fracture behavior is ensured. The specific criteria and limitations are explained in Chapter 3 in detail. The limitations and criteria include the following:

a. Geometric Limitations: Limits were imposed on a number of geometric characteristics to ensure that future bridges are similar in overall configuration and layout to those used to develop the criteria.

b. Pre-Fracture Dead Load Displacement Limitations: The ratio of the length of the span (where the fracture is assumed to occur) to the pre-fracture dead load displacement (of that span) was found to heavily influence the overall load redistribution characteristics of the bridge. When the ratio is "low," a significant amount of displacement will be observed in the fractured girder following a fracture. With lower ratios (i.e., a more flexible bridge), the relative displacement between the intact and the fractured girder increases significantly. This will generally cause localized or even significant plasticity in the concrete deck or steel girders and possible buckling in negative moment regions. However, bridges which were found to satisfy the requirements of the AASHTO Guide Specifications (AASHTO, 2018) all possessed certain dead load deflection characteristics in the unfaulted state. These characteristics were used to develop the deflection criteria proposed herein. 
2. Chapter 4 explains the proposed steps for designing a new twin-tub girder bridge without explicitly modeling fracture while ensuring acceptable post-fracture behavior. An attractive feature of this approach is that it simply utilizes the pre-fracture resistance capacities under the AASHTO LRFD (AASHTO, 2020) Strength I load combination.

In the discussion below, it will be shown that postfracture demands (i.e., those because of Redundancy I and II in the faulted state required by the AASHTO Guide Specifications (AASHTO, 2018)) are satisfied by setting additional limitations on the demand/capacity ratios associated with the Strength I loading in the unfaulted state.

The proposed approach ensures the following failure modes are prevented:

a. Properly designed and detailed studs have also been shown to be critical in the post-fracture performance of twin-tub girder bridges. To increase ductility for concrete breakout capacity, shear studs shall extend a minimum of 2 inches above bottom layer of reinforcement. As discussed below, the proposed methodology specifies the required placement and geometry of intermediate diaphragms to avoid shear stud pull-out.

b. The load after fracture is primarily redistributed from the faulted girder to the intact girder through the intermediate diaphragms. This report provides minimum section details, location and number of intermediate diaphragms to ensure adequate load transfer in the faulted state.

c. The parametric study has demonstrated that bottom flange local buckling in the negative moment region is the most likely failure mode in the faulted state due to the redistribution of positive moment in span which contains the fracture. It is also important to note that the most critical section may not be directly over the pier. For example, wherever the bottom flange section changes, the thinner section's capacity needs to be sufficient to avoid local bottom flange buckling in the post-fracture behavior. To eliminate this form of failure, locations of flange thickness changes are recommended based on the parametric study as a function of span length. Thus, using a very simply criterion, this failure mode can be prevented. It has also been observed that the maximum pre-fracture dead load displacement is a strong indicator of the potential for bottom flange buckling in the faulted state.

d. After fracture occurs, a significant amount of the load is redistributed from the fractured girder to the intact girder. In the fractured span, the positive moment flexural resistance of the intact girder should be checked. The most critical location for this check is at the maximum positive moment closest to the assumed fracture.

e. Shear in the web increases close to the pier and abutment in the intact girder following a fracture. It is recognized that shear stresses in the web are combined with total direct shear and shear due to torsion. However, the use of intermediate diaphragms detailed as prescribed in the proposed criteria combined with span continuity reduce the change between pre- and post-fracture torque significantly. It will be shown that when the proposed criteria are met, failure due to shear is not a concern.

f. When the proposed criteria related to deflection and diaphragm detailing are met, excessive cracking due to flexure, shear, and torsion cracking that would compromise the overall performance of the bridge will not occur when designed and detailed to meet typical AASHTO Strength I requirements.

g. Finally, when the criteria proposed herein are satisfied, it is not necessary to check; (1) changes in support reactions and displacements, (2) post-fracture vertical displacement, and (3) internal and lateral brace failures.

\section{GUIDE LIMITATIONS}

\subsection{Geometric Limitations}

Geometric limitations were developed to ensure the desired post-fracture behavior is achieved. These limitations are based on the types of bridges analyzed in the Wisconsin study that were used to develop the simplified methodology (Korkmaz et al., 2018). Details of the 18 bridge units used in this study are shown below in Table 2.1. In order for the methodology to apply, the following limitations need to be satisfied:

- Minimum two continuous spans: The methodology is only applicable to bridges with two or more continuous spans.

- Composite section with properly detailed studs: The methodology is only applicable to bridges designed for full composite action.

- Maximum total deck width 50 feet: During the parametric study, maximum deck width was 45.896 feet shown in Table 3.1. Hence a limit of 50 feet was selected.

- Maximum number of design lanes $\leq 3$ : All of the bridges analyzed during the parametric study possessed three or fewer design lanes.

- Center to center girder spacing $\leq 25$ feet: As shown in Table 3.1, maximum center to center girder spacing was 25 feet. Hence a limit of 25 feet was selected.

- 60 inches $\leq$ Web height $\leq 90$ inches: All of the bridges analyzed during the parametric study had web heights between 60 and 90 inches (shown in Table 2.1).

- 70 feet $\leq$ Interior span length $\leq 250$ feet: As shown Table 2.1, all of the bridges analyzed during the parametric study had spans lengths between 70 and 250 feet. The methodology was developed for span lengths within this range.

- 100 feet $\leq$ Exterior span length $\leq 200$ feet: The reason for limiting exterior span length is the same as the reason for limiting interior span length.

- $0.60 \leq$ Adjacent span length/Fractured span length $\leq$ 1.70: All bridges included in the study fell within this criterion.

- $1.85 \leq$ Radius of Curvature/Longest span length: All bridges included in the study fall within this criterion.

- Maximum skew $\leq 10$ degrees: All of the bridges analyzed during the parametric study had a skew less than 10 degrees.

\subsection{Pre-Fracture Dead Load Displacement Limitations}

The ratio of span length to pre-fracture (unfactored) dead load displacement has been found to be a useful predictor in providing insight into the expected 
TABLE 2.1

The details of 18 bridge units for WisDOT used in the parametric study

\begin{tabular}{|c|c|c|c|c|c|c|c|c|c|}
\hline Bridge & Units & \# Span & $\begin{array}{c}\text { Deck } \\
\text { Width } \\
\text { (ft.) }\end{array}$ & $\begin{array}{c}\text { Girder } \\
\text { Spacing } \\
\text { (ft.) }\end{array}$ & $\begin{array}{c}\text { Web } \\
\text { Height } \\
\text { (in.) }\end{array}$ & $\begin{array}{c}\text { Span Lengths (L) (ft.) } \\
\text { (Fractured) }\end{array}$ & $\begin{array}{c}\text { Maximum } \\
\text { Adjacent Span } \\
\text { Length/Fractured } \\
\text { Span Length } \\
\end{array}$ & $\begin{array}{c}\text { Minimum } \\
\text { Adjacent Span } \\
\text { Length/Fractured } \\
\text { Span Length } \\
\end{array}$ & $\begin{array}{c}\text { Curvature } \\
\text { Over Longest } \\
\text { Span Length }\end{array}$ \\
\hline \multirow[t]{2}{*}{ B05-658 } & Unit-1 & 4 & 35.896 & 19.0 & 86 & $170-210-210-169$ & 1.24 & 0.80 & 6.49 \\
\hline & Unit-2 & 6 & & & & $199-250-250-250-235-170$ & 1.38 & 0.72 & 5.45 \\
\hline B05-661 & - & 2 & 35.896 & 19.0 & 72 & $187-187$ & 1.00 & 1.00 & 7.20 \\
\hline \multirow[t]{3}{*}{ B05-678 } & Unit-3 & 4 & 44.896 & 25.0 & 86 & $137-192-229-180$ & 1.40 & 0.72 & 6.15 \\
\hline & Unit-4 & 4 & & & & $176-241-241-176$ & 1.37 & 0.73 & 5.85 \\
\hline & Unit-5 & 5 & & & & $151-247-247-247-146$ & 1.69 & 0.59 & 5.70 \\
\hline \multirow[t]{2}{*}{ B05-679 } & Unit-1 & 5 & 44.896 & 25.0 & 86 & $168-248-248-248-170$ & 1.48 & 0.68 & 5.68 \\
\hline & Unit-2 & 5 & & & & $170-248-248-248-181$ & 1.46 & 0.69 & 5.68 \\
\hline B40-776 & - & 3 & 41.896 & 21.0 & 60 & $105-102-105$ & 1.03 & 0.97 & 2.17 \\
\hline B40-783 & - & 3 & 31.896 & 16.0 & 60 & $111-111-119$ & 1.07 & 0.93 & 1.85 \\
\hline \multirow[t]{2}{*}{ B40-786 } & Unit-1 & 4 & 44.896 & 23.0 & 84 & $150-215-215-160$ & 1.43 & 0.70 & 3.91 \\
\hline & Unit-2 & 4 & & & & $146-196-196-140$ & 1.40 & 0.71 & 4.30 \\
\hline B40-834 & - & 3 & 41.896 & 21.0 & 60 & $112-73-116$ & 1.59 & 0.63 & 1.88 \\
\hline B40-837 & - & 2 & 29.896 & 16.0 & 60 & $100-100$ & 1.0 & 1.00 & 2.13 \\
\hline \multirow[t]{2}{*}{ B40-854 } & Unit-1 & 5 & 44.896 & 23.0 & 84 & $146-225-225-194-136$ & 1.54 & 0.65 & 6.64 \\
\hline & Unit-3 & 3 & & & & $157-220-157$ & 1.40 & 0.71 & 6.79 \\
\hline B40-856 & Unit-2 & 6 & 33.896 & 17.0 & 84 & $151-220-220-200-200-160$ & 1.46 & 0.69 & 6.37 \\
\hline B40-868 & - & 2 & 45.896 & 23.5 & 69 & $123-150$ & 1.22 & 0.82 & 1.90 \\
\hline
\end{tabular}

TABLE 2.2

Dead load displacement vs. inelasticity

\begin{tabular}{|c|c|c|c|c|c|}
\hline Bridge & Units & Deck Crushing & $\begin{array}{l}\text { Plastic Strain in the } \\
\text { Main Girder }\end{array}$ & \# of Diaphragms & $\begin{array}{l}\text { Exterior Span Dead Load } \\
\text { Deflection (Pre-fracture) }\end{array}$ \\
\hline \multirow[t]{2}{*}{ B05-658 } & Unit-1 & No & No & 3 & $\mathrm{~L} / 630$ \\
\hline & Unit-2 & Insignificant & Insignificant & 3 & $\mathrm{~L} / 415$ \\
\hline B05-661 & - & Insignificant & Insignificant & 3 & $\mathrm{~L} / 375$ \\
\hline \multirow[t]{3}{*}{ B05-678 } & Unit-3 & No & No & 3 & $\mathrm{~L} / 545$ \\
\hline & Unit-4 & No & No & 3 & $\mathrm{~L} / 610$ \\
\hline & Unit-5 & No & No & 3 & $\mathrm{~L} / 2160$ \\
\hline \multirow[t]{2}{*}{ B05-679 } & Unit-1 & No & No & 3 & $\mathrm{~L} / 850$ \\
\hline & Unit-2 & No & No & 3 & $\mathrm{~L} / 670$ \\
\hline B40-776 & - & No & Insignificant & 2 & $\mathrm{~L} / 365$ \\
\hline B40-783 & - & No & Insignificant & 2 & $\mathrm{~L} / 410$ \\
\hline \multirow[t]{2}{*}{ B40-786 } & Unit-1 & No & No & 3 & $\mathrm{~L} / 570$ \\
\hline & Unit-2 & No & No & 3 & $\mathrm{~L} / 770$ \\
\hline B40-834 & - & No & Insignificant & 2 & $\mathrm{~L} / 350$ \\
\hline B40-837 & - & No & No & 2 & $\mathrm{~L} / 1250$ \\
\hline \multirow[t]{2}{*}{ B40-854 } & Unit-1 & No & No & 2 & $\mathrm{~L} / 850$ \\
\hline & Unit-3 & No & No & 2 & $\mathrm{~L} / 750$ \\
\hline B40-856 & Unit-2 & No & No & 2 & $\mathrm{~L} / 550$ \\
\hline B40-868 & - & Localized & Localized & 3 & $\mathrm{~L} / 210$ \\
\hline
\end{tabular}

post-fracture behavior. If the displacement is high compared to span length, there will likely be moderate to significant inelastic behavior and the developed methodology will not be able to estimate behavior accurately. A review of the results presented in Table 2.2 shows the level of damage that was observed as function of deflection for structure. Based on the overall behavior of observed, it is apparent that as the flexibility of the bridge in the unfaulted stated increases, so does the level of damage.
Note in particular Bridge B40-868 where the deflections were about L/210 and the level of inelasticity observed almost exceeded the limitations contained in the AASHTO Guide Specifications (AASHTO, 2018). To ensure acceptable performance, a limit was selected based on the worst (i.e., most flexible) performing bridge while adding a bit of conservatism. Hence, using limit of $\mathrm{L}_{\mathrm{F}} / \mathrm{D}_{\mathrm{F}} \geq 300$, it has been determined that this methodology can be applied. This is because the overall structure is too flexible and excessive plasticity may 
occur. In such cases, the engineer would need to analyze the bridge using the provisions of the AASHTO Guide Specifications (AASHTO, 2018). It should be noted here, positive displacements are in the downward direction, whereas negative displacements show upward deflections. This same limit (i.e., $\mathrm{L}_{\mathrm{F}} / \mathrm{D}_{\mathrm{F}} \geq 300$ ) can be conservatively applied to interior spans as well.

\subsection{Bridges Not Within the Limitations}

If the bridge under design or an existing bridge is not within the required limitations, 3D detailed FEA is the most suitable analysis tool to adequately evaluate the redundancy of the twin-tub girder bridges. It is recommended to follow the approach defined in AASHTO Guide Specifications (AASHTO, 2018) and NCHRP Report 883 (Connor et al., 2018). The twintub girder modeling approach should be benchmarked to the three full-scale experiments performed at the University of Texas at Austin (Barnard et al., 2010). A detailed FEA study corresponding to the experiments was also presented in Korkmaz (2018) that may also be used for comparative purposes. It is recommended to develop or replicate the benchmark study from the fullscale testing explained in the NCHRP Report 883 (Connor et al., 2018) to provide confidence in the results. The bridges used in the calibration process were Neville Island Bridge (Connor et al., 2018), Hoan Bridge (Connor et al., 2018), University of Texas Twintub Girder Bridge Experiments (2018), Milton Madison Bridge (Connor et al., 2018), White River Bridge (Connor et al., 2018), and Dan Ryan Expressway Transit Structure (Connor et al., 2018). The twin-tub girder modeling approach could also be benchmarked to the three full-scale experiments performed at the University of Texas at Austin (Barnard et al., 2010). The software used for the detailed FEA should be capable of modeling three-dimensional geometry, material nonlinearity, geometric nonlinearity, material features (density, damping, field variable dependent properties), kinematic constraints, contact (friction and hard), and boundary conditions.

\section{PROPOSED GUIDANCE FOR DESIGNING SRMS IN TWIN-TUB GIRDER BRIDGES}

In this chapter, the development of the proposed simplified guidance will be presented in detail. The guidance was developed using detailed FEA results, bridge plans, and the original design calculations for each bridge. As stated, this included 18 multi-span twintub girder bridge units with a total length in total 2.4 miles and 70 spans in the state of Wisconsin. The FE analysis results were used to obtain the post-fracture demand/capacity ratios under the Redundancy I and II load combinations. These ratios were compared to the demand/capacity ratios under the familiar Strength I load combination or the component capacity.

In many cases, the demand/capacity ratio in the faulted state under the Redundancy load combinations were very low. In addition, in many cases, the demand/ capacity ratio in the faulted state under the Redundancy load combination was almost always less than under Strength I in the unfaulted state. In a few isolated cases, the ratio in the faulted state exceeded the ratio in in the unfaulted state, but only by a few percent. Hence, as will be shown many failure modes listed below will not need to be considered under Redundancy load factors in the faulted state. However, they will be discussed for completeness.

The demand/capacity ratios under the Strength I load combination do provide some insight into the outcome following a fracture. However, they cannot be used directly. In other words, one cannot simply assume acceptable behavior if the Strength I demand/capacity ratios are less than 1.0 in the unfaulted state. For example, for some bridges evaluated, higher demand/capacity ratios were observed under the Redundancy load combinations in the faulted state than were observed under Strength I in the unfaulted state. In such cases, the main concern would be a case where the demand/capacity ratio is acceptable in the unfaulted state but unacceptable in the faulted state. After a detailed evaluation of all the data and all failure modes in all bridges, it was found that by setting additional limits on the Strength I demand/capacity ratios (e.g., limiting $\mathrm{D} / \mathrm{C} \leq 0.8$ for some limit state during design), will ensure adequate headroom for potential increases in faulted stated. The proposed guidance addresses all the failure modes defined in the AASHTO Guide Specifications (AASHTO, 2018). With this simplified guidance, a twin-tub girder bridge whether has FCMs or not can be determined easily.

The proposed guidance ensures the following failure modes are prevented:

1. Shear stud pull-out and shear failure (Section 4.1.1).

2. Flexural and shear failure of intermediate diaphragms (Section 4.1.2).

3. Local bottom flange buckling of the girder in compression (Section 4.1.3).

4. Positive moment flexural failure (girder and deck) (Section 4.1.4)

5. Web shear buckling in the girder (Section 4.1.5).

6. Excessive torsional cracking in the deck according to ACI 318-14 Section 22.7.6 Torsional Strength (Section 4.1.6) (ACI Committee 318, 2014).

7. Excessive concrete cracking in the deck due to flexure or shear (Section 4.1.7).

8. Excessive support reaction increases and unacceptable horizontal displacements (Section 4.1.8).

9. Vertical deflection of the fractured girder is less than L/50 (Section 4.1.8).

\subsection{Stud Pull-Out Failure (Haunch Separation)}

The tensile and shear behavior of shear studs is critical in the load transfer between the steel members and the concrete slab in composite steel bridges as they help provide additional load paths after the failure of a 
TABLE 3.1

Shear stud properties of WisDOT bridges

\begin{tabular}{|c|c|c|c|c|c|c|}
\hline Bridge & Units & $\begin{array}{c}\text { Dead Load Deflection at } \\
\text { First Intermediate Diaphragm } \\
\text { (Pre-fracture) }\end{array}$ & $\begin{array}{c}\# \text { of Shear Stud } \\
\text { Transversely Spaced }\end{array}$ & Stud Height (in.) & Stud Spacing (in.) & Stud Failure \\
\hline \multirow[t]{2}{*}{ B05-658 } & U1 & $\mathrm{L} / 810$ & 3 & 6 & 22 & NO \\
\hline & $\mathrm{U} 2$ & $\mathrm{~L} / 740$ & 3 & 6 & 20 & NO \\
\hline B05-661 & - & $\mathrm{L} / 415$ & 3 & 7 & 17 & YES \\
\hline \multirow[t]{3}{*}{ B05-678 } & U3 & L/865 & 3 & 7 & 12 & NO \\
\hline & U4 & $\mathrm{L} / 890$ & 3 & 7 & 12 & NO \\
\hline & U5 & $\mathrm{L} / 2185$ & 3 & 7 & 12 & NO \\
\hline \multirow[t]{2}{*}{ B05-679 } & U1 & $\mathrm{L} / 1010$ & 3 & 7 & 12 & NO \\
\hline & U2 & $\mathrm{L} / 880$ & 3 & 7 & 12 & NO \\
\hline B40-776 & - & $\mathrm{L} / 460$ & 3 & 7 & 8 & NO \\
\hline B40-783 & - & $\mathrm{L} / 650$ & 3 & 6 & 12 & NO \\
\hline \multirow{2}{*}{ B40-786 } & U1 & $\mathrm{L} / 570$ & 3 & 6 & 12 & NO \\
\hline & $\mathrm{U} 2$ & $\mathrm{~L} / 850$ & 3 & 6 & 12 & NO \\
\hline B40-834 & - & $\mathrm{L} / 430$ & 3 & 8 & 10 & NO \\
\hline B40-837 & - & $\mathrm{L} / 1425$ & 3 & 6 & 9 & NO \\
\hline \multirow[t]{2}{*}{ B40-854 } & U1 & $\mathrm{L} / 1120$ & 3 & 8 & 14 & NO \\
\hline & U3 & $\mathrm{L} / 1070$ & 3 & 8 & 16 & NO \\
\hline B40-856 & $\mathrm{U} 2$ & $\mathrm{~L} / 765$ & 3 & 6 & 12 & $\mathrm{NO}$ \\
\hline B40-868 & - & $\mathrm{L} / 270$ & 3 & 8 & 9 & YES \\
\hline
\end{tabular}

primary steel member. The superior ability of composite steel bridges to transfer load was shown by Bernard et al. (2010), who performed full-scale experiments in a simple span twin-tub girder bridge that underwent failure of the bottom flange and web of one of the tub girders. Therefore, given their essential role in composite action, shear studs need to be designed properly to make to the bridge stay in composite behavior in the post-fracture performance of twin-tub girder bridges.

In some of the WisDOT bridges a few isolated shear stud failures were observed but were not found to be critical. Hence, the overall layout of the studs in these bridges provide a template for how to layout studs in other bridges since they exhibited very good performance. Using that data and the observed behavior, a simplified set of criteria were developed that ensure no shear studs will pull-out of the deck in the faulted state.

It is also noted that the behavior of shear studs (i.e., the tension demand) was found to be directly affected by the pre-fracture (unfactored) dead load displacement at the location where the first intermediate diaphragm is located. According to Table 3.1, two of the bridges (B05-661 and B40-868) had the first diaphragm placed at the location where the dead deflection was more than L/500. In these two bridges (and only these two bridges), some isolated shear stud failures were observed. There were no other failures in any of the other bridges when the first diaphragm was located where the dead deflection was less than L/500. Therefore, it is proposed that the first diaphragm be placed as close as practical to the location where the pre-fracture dead load deflection is less than L/500 to avoid shear stud failure.
The specific guidance on how to best detail and layout shears studs were developed by using the layouts found in the Wisconsin bridges as a starting point and the recommendations from the research at the University of Texas at Austin (Barnard et al., 2010). Table 3.1 presents the layouts of the shear studs in the family of bridges included in the study. Based on these data, the following recommendations are:

1. To ensure the shear studs are evenly distributed and ensure continuity, the maximum longitudinal spacing between studs should not be more than three times the effective stud height (i.e., height of shaft) as specified in the AASHTO Guide Specification (AASHTO, 2018).

2. The layout of all shear studs was obtained from the design plans and summarized in Table 3.1. It is noted that for all of the bridges considered, three shear studs were placed transversely on the flange. The shear stud design and detailing was based on the AASHTO requirements that are used in normal design and do not consider tension pull-out. In all cases, the "normal" design requirements which apply before a fracture, provided more than sufficient shear and tension pullout capacity in the faulted state. It was found that when all other criteria contained in these proposed guidelines are satisfied, the normal AASHTO shear stud design will ensure adequate performance in the faulted state. Since the greatest longitudinal spacing that was included in the study was 22 inches, this was selected as an upper limit when three shear studs are used transversely.

3. In cases where two studs are to be placed transversely, it is proposed to simply use a maximum longitudinal spacing for two studs that is $2 / 3$ of the maximum longitudinal spacing used for three studs, or 14 inches (2/ $3 \times 2^{\prime \prime} \approx 14^{\prime \prime}$.

4. Based on the AASHTO Guide Specifications (AASHTO, 2018), the minimum edge distance between outermost 
TABLE 3.2

WisDOT bridges girder top flanges vs. diaphragm top flanges

\begin{tabular}{|c|c|c|c|c|c|c|}
\hline Bridge & Units & $\begin{array}{c}\text { Minimum Top Flange } \\
\text { Size in Longest } \\
\text { Exterior Span (in.) }\end{array}$ & $\begin{array}{c}\text { Minimum Web } \\
\text { Size in Longest } \\
\text { Exterior Span (in.) }\end{array}$ & $\begin{array}{l}\text { Diaphragm Top } \\
\text { Flange Section (in.) }\end{array}$ & $\begin{array}{c}\text { Diaphragm Web } \\
\text { Section (in.) }\end{array}$ & $\begin{array}{c}\text { Post-Fracture } \\
\text { Demand/Capacity }\end{array}$ \\
\hline \multirow[t]{2}{*}{ B05-658 } & U1 & $20 \times 1$ & $86 \times 3 / 4$ & $20 \times 7 / 8$ & $86 \times 3 / 4$ & 0.44 \\
\hline & U2 & $22 \times 1$ & $86 \times 3 / 4$ & $20 \times 7 / 8$ & $86 \times 3 / 4$ & 0.59 \\
\hline B05-661 & - & $22 \times 1$ & $72 \times 3 / 4$ & $20 \times 7 / 8$ & $72 \times 3 / 4$ & 0.38 \\
\hline \multirow[t]{3}{*}{ B05-678 } & U3 & $22 \times 1$ & $86 \times 3 / 4$ & $20 \times 1$ & $86 \times 3 / 4$ & 0.58 \\
\hline & U4 & $22 \times 1$ & $86 \times 3 / 4$ & $20 \times 1$ & $86 \times 3 / 4$ & 0.57 \\
\hline & U5 & $22 \times 1$ & $86 \times 3 / 4$ & $20 \times 1$ & $86 \times 3 / 4$ & 0.47 \\
\hline \multirow[t]{2}{*}{ B05-679 } & U1 & $22 \times 1$ & $86 \times 3 / 4$ & $20 \times 1$ & $86 \times 3 / 4$ & 0.49 \\
\hline & U2 & $22 \times 1$ & $86 \times 3 / 4$ & $20 \times 1$ & $86 \times 3 / 4$ & 0.47 \\
\hline B40-776 & - & $18 \times 3 / 4$ & $60 \times 5 / 8$ & $16 \times 3 / 4$ & $60 \times 1 / 2$ & 0.73 \\
\hline B40-783 & - & $18 \times 3 / 4$ & $60 \times 5 / 8$ & $16 \times 3 / 4$ & $60 \times 1 / 2$ & 0.46 \\
\hline \multirow[t]{2}{*}{ B40-786 } & U1 & $20 \times 1$ & $84 \times 5 / 8$ & $16 \times 1$ & $84 \times 5 / 8$ & 0.62 \\
\hline & U2 & $20 \times 1$ & $84 \times 5 / 8$ & $16 \times 1$ & $84 \times 5 / 8$ & 0.72 \\
\hline B40-834 & - & $18 \times 3 / 4$ & $60 \times 5 / 8$ & $16 \times 3 / 4$ & $60 \times 1 / 2$ & 0.87 \\
\hline B40-837 & - & $16 \times 3 / 4$ & $60 \times 5 / 8$ & $16 \times 3 / 4$ & $60 \times 1 / 2$ & 0.46 \\
\hline \multirow{2}{*}{ B40-854 } & U1 & $22 \times 1$ & $84 \times 11 / 16$ & $16 \times 1$ & $84 \times 5 / 8$ & 0.42 \\
\hline & U3 & $20 \times 7 / 8$ & $84 \times 11 / 16$ & $16 \times 1$ & $84 \times 5 / 8$ & 0.58 \\
\hline B40-856 & $\mathrm{U} 2$ & $20 \times 1$ & $84 \times 5 / 8$ & $16 \times 1$ & $84 \times 5 / 8$ & 0.61 \\
\hline B40-868 & - & $20 \times 7 / 8$ & $69 \times 11 / 16$ & $16 \times 3 / 4$ & $69 \times 1 / 2$ & 0.82 \\
\hline
\end{tabular}

stud and edge of haunch should be a minimum $1.5 \mathrm{inch}$ This limitation is adopted here.

5. Based on the work at Mouras et al. (2008), in order to provide increased ductility for concrete breakout capacity, shear studs should extend a minimum of two inches above the bottom layer of reinforcement.

\subsection{Intermediate Diaphragm Web Shear and Flexural Yielding}

Intermediate diaphragms are required to be designed to guarantee adequate load distribution between girders in the faulted state. The required size, location and the number of the intermediate diaphragms proposed herein is also based on the details observed in the Wisconsin Bridges. In the bridges evaluated, the intermediate diaphragms were full-depth and full-width and include both internal and external sections between the girders. Hence, this recommendation is included in the proposed guidance. It is also recommended that the same basic cross-section be used between and within the girders. Obviously, the diaphragms between the girders only need to have top flanges whereas external diaphragm requires to include both bottom and top flanges. It is recommended to provide shear studs on the top flanges of the diaphragms to increase stiffness, though it is not required to achieve acceptable performance.

\subsubsection{Diaphragm Plate Size Recommendations}

The details of the diaphragms used in the existing bridges analyzed in Phase I (Korkmaz et al., 2018) are shown in Table 3.2. In all cases, the diaphragms were capable of transferring both shear and moment during post-fracture behavior and in most cases had substantial reserve strength. Further, the FEA also confirmed these diaphragms also possessed adequate stiffness to transfer the load to the intact girder. The demand/capacities of the intermediate diaphragms in the faulted state were calculated and are summarized in Table 3.2. (It is noted that the value listed is the worst case from flexure, shear, and combined flexure and shear.) It is clear that in almost every case there is significant reserve strength in the faulted state.

A study of Table 3.2 reveals that the flange sections of the diaphragm ( 5 th column) were never larger than the top flange sections used in the minimum exterior span exterior girder (3rd column). For simplicity, it is proposed that the top and bottom flanges of the diaphragms be the same as the smallest top flange used in the longer exterior span. While this is conservative, it will provide adequate stiffness and hence load distribution. Similarly, it is also proposed that the web sections of the diaphragms be equal to minimum web section of the longer exterior span exterior girder. The connections should be designed using normal AASHTO procedures.

\subsubsection{Recommended Number and Location of the Diaphragms}

The optimal number and location of the diaphragms in a span were studied to understand how to (1) distribute the loads between the intact and fractured spans; (2) reduce the post-fracture moment at the pier; and (3) minimize the damage to the deck; and (4) eliminate shear stud pull-out failures. As shown in Figure 3.1, the total moment change at the pier is the greatest when no diaphragms were included as expected. (Note this figure presents the total change in moment or in other words, the summation of the change in moment in both girders at the pier). It can be seen that the total 


\section{Different Diaphragm Locations}



Figure 3.1 Total moment change considering different diaphragm locations-L/8 increments.

moment change was also large when only two diaphragms were placed at the eighth points $(1 / 8$ and $7 / 8)$ or the quarter points $(2 / 8$ and $6 / 8)$. The lowest changes were observed when the first diaphragm is located at about $30 \%$ of the span length and the second diaphragms is placed symmetrically within the span. Similar behavior is observed when three diaphragms are used if one is located in the middle of the span (see Figure 3.1).

It is also very important to note that the number and location of the diaphragms has a significant influence on the distribution of the negative moment transferred to the pier between the girders. The behavior is shown in Figure 3.2. In the figure, the fracture is assumed to be located in the exterior girder. Note that nearly all of the moment transferred to the pier remains in the fractured girder when no diaphragms are present. This is because the concrete deck alone is not stiff enough to transfer the load into the intact girder. Thus, it is not valid to simply assume that all the load is transferred to the intact girder (for both negative and positive moment) as some other simplified approaches have proposed. While this may appear to be a conservative assumption (i.e., that all the load in the fractured girder is transferred to the intact girder), there must also be a valid load path to satisfy the assumption. Since the deck is very flexible, especially after longitudinal cracking begins, the faulted girder simply deflects, and the moment is transferred to the pier when no diaphragms are present. Thus, the fractured girder carries nearly all of the redistributed moment at the pier location and very little of the moment is transferred to the intact girder. This is shown clearly in Figure 3.2. Studies have shown that this can result in buckling of the fractured girder in the negative moment region Korkmaz (2018). In short, the deck alone is not capable of reliably distributing the moments between the fractured and intact girder when considering negative moment at the pier. The parametric study has confirmed that properly spaced and detailed diaphragms are required in multi-span bridges.
As stated, the location and number of the diaphragms is important in ensuring acceptable behavior. For example, it is obvious that a diaphragm placed just a few feet from a support will do little in transferring load to the intact girder following a fracture at midspan (see Figure 3.2). Hence, it is important to develop criteria prescribing the placement and number of diaphragms.

After much study, it was found that the placement and quantity of the intermediate diaphragms can be easily determined in relation to the pre-fracture dead load deflection. For exterior spans, if the dead load deflection at $30 \%$ of the span length $(0.3 \mathrm{~L})$ from the abutment is less than or equal to L/500, two intermediate diaphragms are recommended. The first diaphragm should be placed between $0.3 \mathrm{~L}$ and $0.4 \mathrm{~L}$ and should not be located beyond the location where the displacement is equivalent to $\mathrm{L} / 500$. The second diaphragm should be placed symmetrically within the same span. If the deflection at $30 \%$ of the span length $(0.3 \mathrm{~L})$ is more than $\mathrm{L} / 500$, the study found that a minimum of three intermediate diaphragms should be placed in the span. The first diaphragm should be placed as close as practical to the location where the deflection is L/500. The second diaphragm should be placed at mid-span. The third diaphragm should be placed symmetrically with the first diaphragm within the span. For interior spans, two intermediate diaphragms should be placed as close as is practical to the third points of the span. The intermediate diaphragms of interior spans should possess the same cross-section as the exterior span diaphragms.

\subsubsection{Local Bottom Flange Buckling in Negative Moment Zone}

Korkmaz (2018) noted that bottom flange buckling might be one of the most common post-fracture failure mode under Redundancy load factors. The bottom flanges are commonly made of slender or non-compact 


\section{Different Diaphragm Locations}

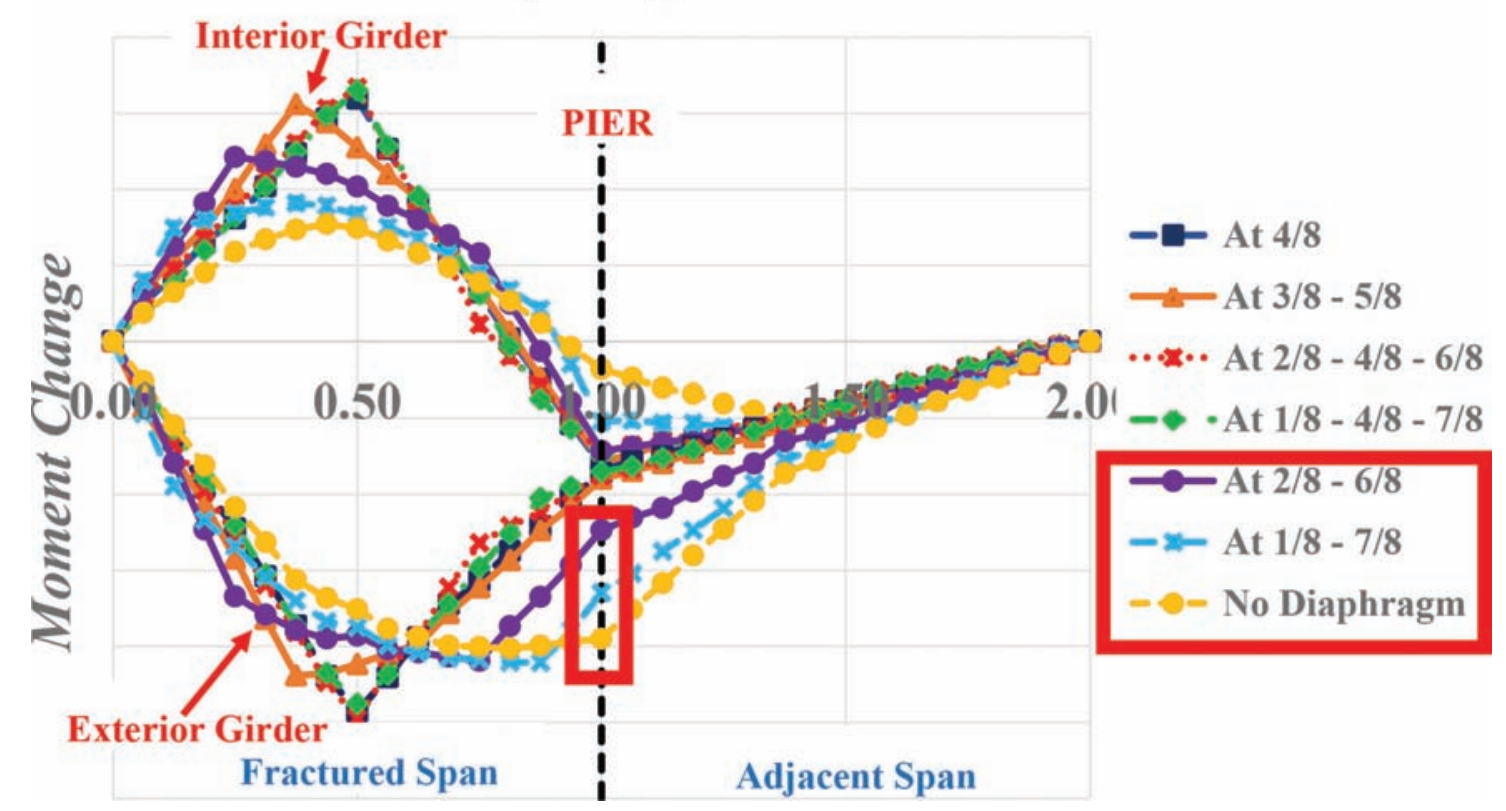

Figure 3.2 Post-fracture moment in the girders considering different diaphragm locations - L/8 increments.

\section{Bottom flange buckling next to pier at the fracture girder}

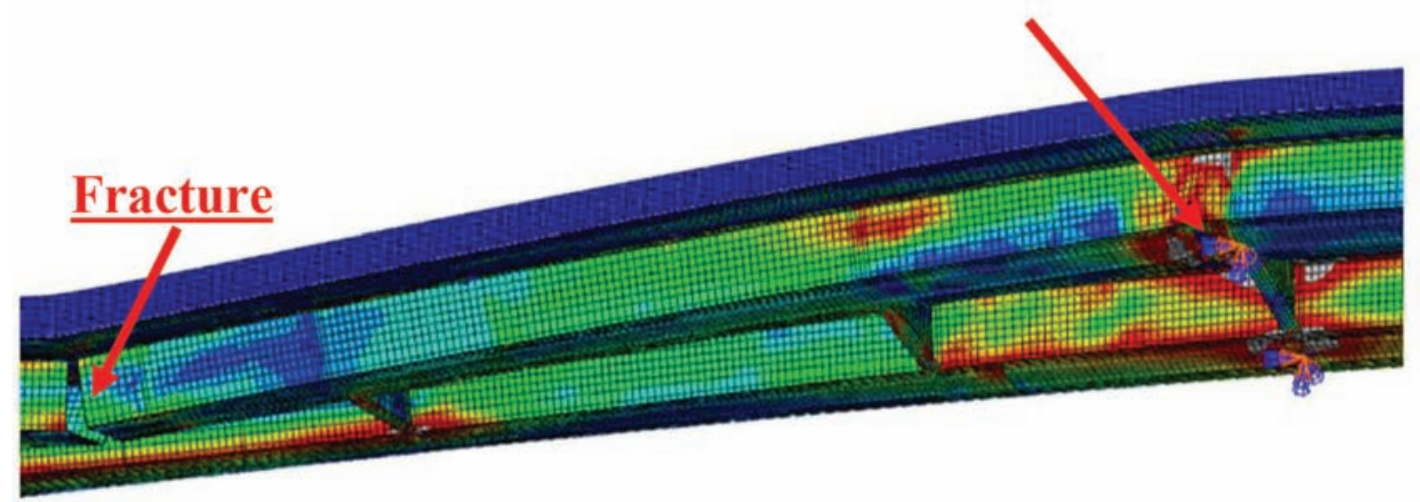

Figure 3.3 Fractured girder local bottom flange buckling next to pier in fractured span.

sections in twin-tub girder bridges. As observed in Figure 3.3, one of the most critical sections is directly over the pier and it must be evaluated in both the intact and fractured girders in the fractured span as well as in the adjacent span. However, another, often more critical location is wherever the bottom flange changes thickness, as shown in Figure 3.4 (i.e., at a flange transition).

To develop simple criteria for preventing this failure mode, the local buckling capacities and design stresses were compared at the pier and where the sections change both in exterior spans and interior spans for all bridges. The local buckling capacities, the longitudinal stresses from design calculations, and the maximum nominal longitudinal stresses from the FEA were compared at the center of the bottom flange of the fractured girder at the pier and at the bottom flange transition closest to the pier.

As can be seen in Table 3.3, the demand/capacity ratios for buckling in the design calculations were always higher than those in the faulted stated directly over the pier (see column 3). This strongly suggests that when the other criteria are met (i.e., overall geometry, dead load deflection and diaphragm requirements), local bottom flange buckling at the pier is unlikely in the faulted state. The main reason for this is that the negative moments generated in Strength I are greater than those produced during Redundancy load combinations in the faulted state. Interestingly, as shown in Table 3.3, where there is a bottom flange thickness transition, the ratios are more critical in the faulted state than under Strength I in some cases. Based on 


\section{Thinner section bottom flange buckling at the section change in}

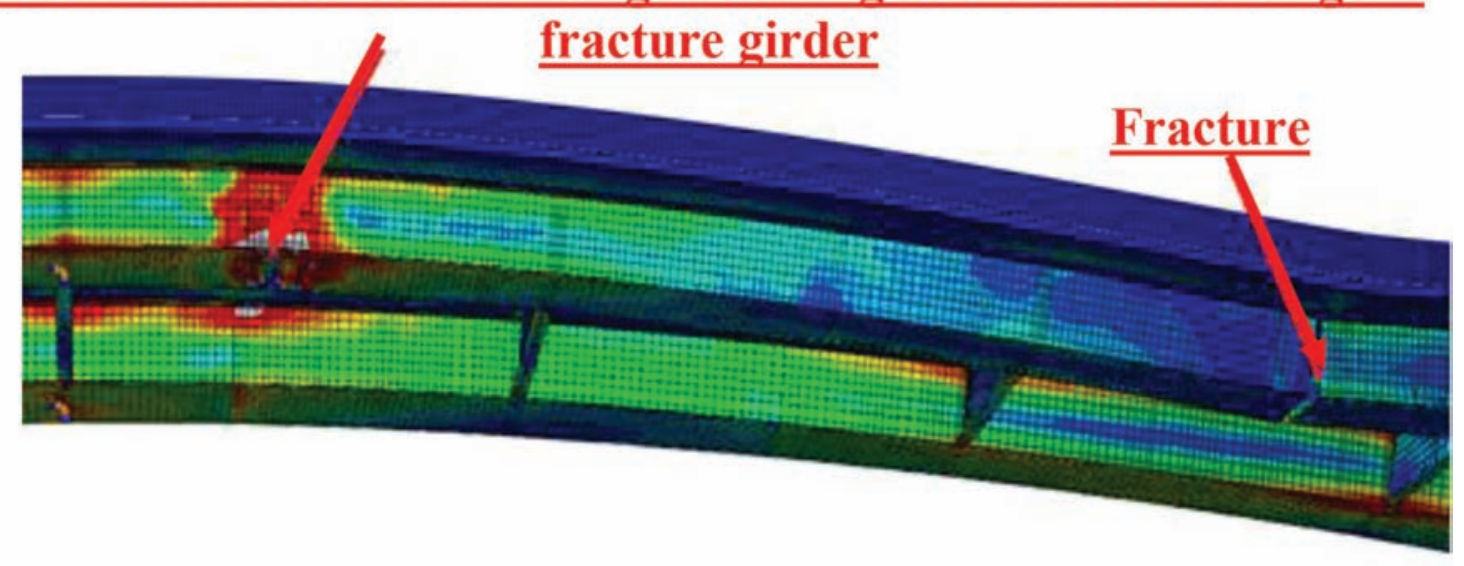

Figure 3.4 Fractured girder thinner section local bottom flange buckling at the section change in fractured span.

these observations, guidance was developed regarding where to locate flange thickness transitions and a corresponding recommended maximum demand/capacity ratio under Strength I load combinations to prevent this failure mode. Used together, these two criteria ensure bottom flange buckling will not occur in the faulted state.

\subsubsection{Recommended Criteria to Prevent Flange} Buckling. According to a close study of Table 3.3, there is really no need to check the sections between the pier for a distance of $0.2 \mathrm{~L}$ away from this pier, since all of the demand/capacity ratios under Strength I are generally higher than those produced in the faulted state using the Redundancy load combinations. Thus, no additional criteria appear needed in this region (see column 4 through 7 of Table 3.3). However, to avoid the high demand/capacity ratios in the faulted state at a flange transition between $0.2 \mathrm{~L}$ and $0.3 \mathrm{~L}$ away from a pier, (see column 4 through 7 of Table 3.3). For the sections between $0.2 \mathrm{~L}$ and $0.3 \mathrm{~L}$ away from a pier, the pre-fracture demand/capacity ratio should be less than 0.7 for the Strength I load combination. The sections more than $0.3 \mathrm{~L}$ away from a pier do not need to be checked.

Additional FE analysis was to evaluate the criticality of buckling in the negative moment region when a fracture is assumed to occur within an interior span. Due to the double cantilever behavior at an interior span, the effects were found to be insignificant does not need to be considered. In summary, it was observed that fracture in an end or exterior span was more critical than a fracture within an interior span.

\subsubsection{Flexural Yielding in Positive Moment Region of Flanges in Intact Girder}

As expected, a significant amount of the load is redistributed from the fractured girder to the intact girder. In the fractured span, the flexural resistance of the positive moment capacity of the intact girder should be checked. The most critical location for this check is at the maximum positive moment closest to the assumed fracture.

When the intact girder substantially exceeds its elastic moment capacity, the post-fracture moment redistribution is difficult to estimate with simplified methods. For example, a considerable amount of plasticity in the positive moment region causes more moment to be redistributed to the cross-sections close to the pier. The overall method developed herein ensures there will be little to no yielding in the positive moment region of the intact girder.

A review of Table 3.4 reveals that when the prefracture demand/capacity ratio in the exterior girder under Strength I load combinations is less than 0.8, no plasticity was observed in intact girder for post-fracture behavior. It is therefore proposed to limit the prefracture demand/capacity ratio less than or equal to 0.8 for both girders.

\subsubsection{Web Shear Failure Close to Pier and Abutment in Intact Girder}

In the parametric studies, this failure mode was only observed in simple span bridges and when loads in excess of the Redundancy load combinations were applied. This behavior is illustrated for informational purposes as shown in Figure 3.5 which was developed during a portion of the work in which simple span bridges were evaluated. However, in continuous span bridges that are within the span and stiffness criteria outlined above, increases in web shear close to the pier and at the abutment only in the intact girder were generally found to be small. As expected, there was no increase in shear observed in a fractured girder, therefore it does not have to be studied in that location. Only the fractured span needed to be evaluated. It should be noted here that shear stresses on the web are combined with direct shear and shear due to torque. 


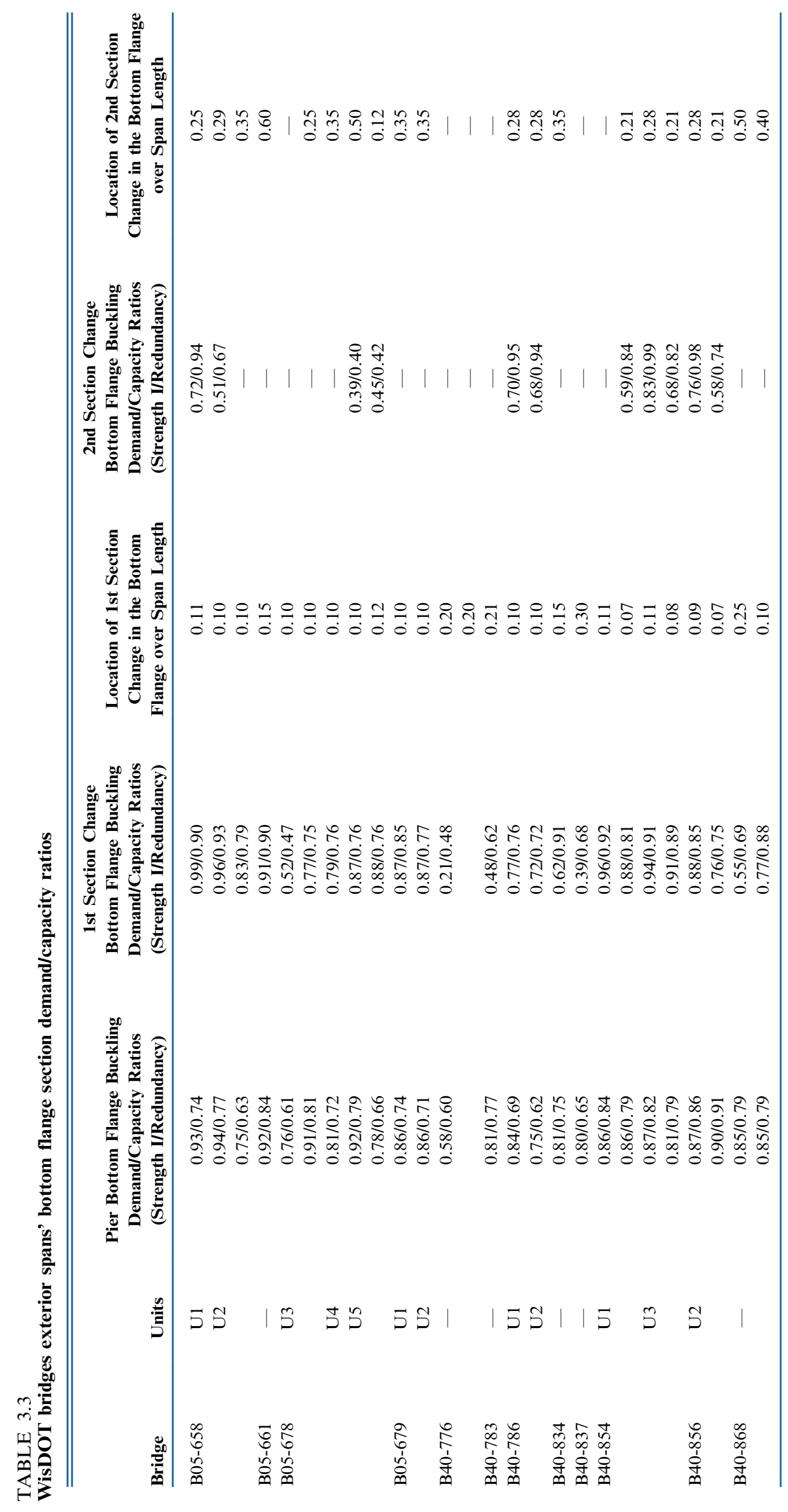


TABLE 3.4

WisDOT bridges flexural moment in tension demand/capacity ratios

\begin{tabular}{|c|c|c|c|c|}
\hline Bridge & Units & $\begin{array}{c}\text { Interior Girder Exterior Span Flexure in } \\
\text { Positive Moment Demand/Capacity } \\
\text { Ratios (Strength I) }\end{array}$ & $\begin{array}{c}\text { Exterior Girder Exterior Span Flexure } \\
\text { in Positive Moment Demand/Capacity } \\
\text { Ratios (Strength I) }\end{array}$ & $\begin{array}{c}\text { Interior Girder Exterior Span Flexure } \\
\text { in Positive Moment Demand/Capacity } \\
\text { Ratios After Fracture (Redundancy) }\end{array}$ \\
\hline \multirow[t]{2}{*}{ B05-658 } & U1 & 0.59 & 0.59 & 0.61 \\
\hline & $\mathrm{U} 2$ & 0.70 & 0.70 & 0.93 \\
\hline B05-661 & - & 0.75 & 0.75 & 0.80 \\
\hline \multirow[t]{5}{*}{ B05-678 } & U3 & 0.41 & 0.41 & 0.54 \\
\hline & & 0.62 & 0.62 & 0.83 \\
\hline & U4 & 0.59 & 0.59 & 0.79 \\
\hline & U5 & 0.39 & 0.39 & 0.55 \\
\hline & & 0.37 & 0.37 & 0.51 \\
\hline \multirow[t]{2}{*}{ B05-679 } & U1 & 0.39 & 0.39 & 0.51 \\
\hline & $\mathrm{U} 2$ & 0.57 & 0.57 & 0.76 \\
\hline B40-776 & - & 0.50 & 0.57 & 0.67 \\
\hline B40-783 & - & 0.56 & 0.64 & 0.74 \\
\hline \multirow[t]{2}{*}{ B40-786 } & U1 & 0.68 & 0.75 & 0.95 \\
\hline & $\mathrm{U} 2$ & 0.62 & 0.66 & 0.89 \\
\hline B40-834 & - & 0.57 & 0.60 & 0.77 \\
\hline B40-837 & - & 0.36 & 0.37 & 0.48 \\
\hline \multirow[t]{4}{*}{ B40-854 } & U1 & 0.46 & 0.47 & 0.61 \\
\hline & & 0.49 & 0.50 & 0.63 \\
\hline & U3 & 0.49 & 0.50 & 0.63 \\
\hline & & 0.50 & 0.51 & 0.64 \\
\hline \multirow[t]{2}{*}{ B40-856 } & $\mathrm{U} 2$ & 0.65 & 0.68 & 0.81 \\
\hline & & 0.78 & 0.81 & 1.05 \\
\hline \multirow[t]{2}{*}{ B40-868 } & - & 0.40 & 0.46 & 0.53 \\
\hline & & 0.71 & 0.79 & 0.89 \\
\hline
\end{tabular}

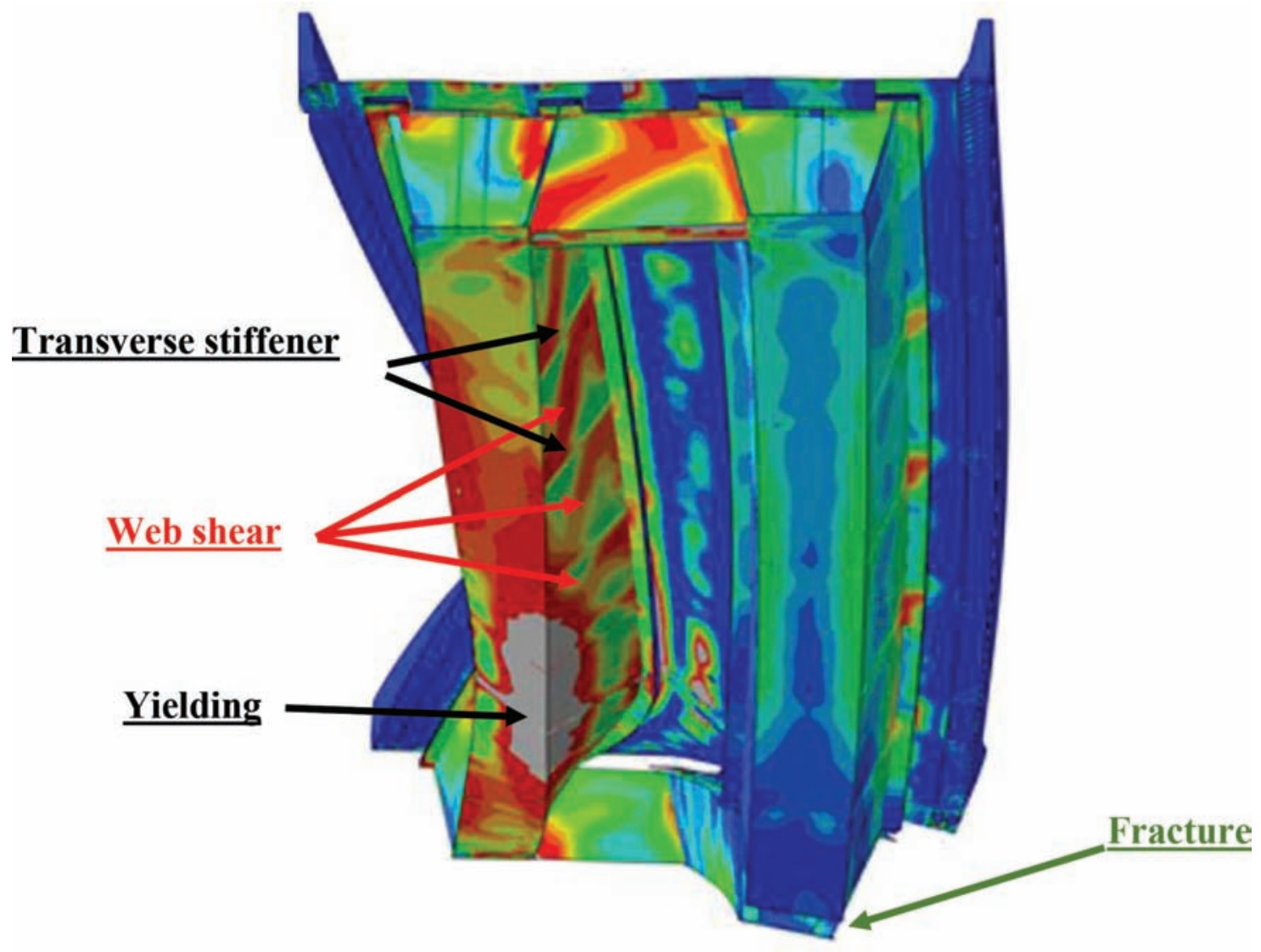

Figure 3.5 Web shear failure in a simple span bridge. 
TABLE 3.5

WisDOT web shear demand/capacity ratios

\begin{tabular}{|c|c|c|c|}
\hline Bridge & Units & $\begin{array}{l}\text { Interior Girder Web Shear Demand/ } \\
\text { Capacity Ratios (Strength I) }\end{array}$ & $\begin{array}{l}\text { Interior Girder Exterior Span Flexure in Positive } \\
\text { Moment Demand/Capacity Ratios (Redundancy) }\end{array}$ \\
\hline \multirow[t]{2}{*}{ B05-658 } & U1 & 0.37 & 0.55 \\
\hline & U2 & 0.43 & 0.62 \\
\hline B05-661 & - & 0.56 & 0.47 \\
\hline \multirow[t]{5}{*}{ B05-678 } & U3 & 0.46 & 0.71 \\
\hline & & 0.62 & 0.83 \\
\hline & U4 & 0.51 & 0.68 \\
\hline & U5 & 0.51 & 0.61 \\
\hline & & 0.37 & 0.51 \\
\hline \multirow[t]{2}{*}{ В05-679 } & U1 & 0.50 & 0.59 \\
\hline & U2 & 0.51 & 0.60 \\
\hline B40-776 & - & 0.52 & 0.62 \\
\hline B40-783 & - & 0.73 & 0.62 \\
\hline \multirow[t]{2}{*}{ B40-786 } & U1 & 0.68 & 0.75 \\
\hline & U2 & 0.62 & 0.61 \\
\hline B40-834 & - & 0.57 & 0.59 \\
\hline B40-837 & - & 0.36 & 0.29 \\
\hline \multirow[t]{4}{*}{ B40-854 } & U1 & 0.70 & 0.81 \\
\hline & & 0.58 & 0.64 \\
\hline & U3 & 0.40 & 0.60 \\
\hline & & 0.37 & 0.51 \\
\hline \multirow[t]{2}{*}{ B40-856 } & U2 & 0.64 & 0.64 \\
\hline & & 0.78 & 0.72 \\
\hline \multirow[t]{2}{*}{ B40-868 } & - & 0.53 & 0.45 \\
\hline & & 0.30 & 0.28 \\
\hline
\end{tabular}

According to Table 3.5, the post-fracture demand/ capacity ratio in the intact interior girder under the Redundancy load combinations were never found to be critical. Therefore, it is concluded that for bridges meeting the criteria (geometry, stiffness, possessing diaphragms) web shear buckling does not need be checked under post-fracture behavior.

\subsubsection{Excessive Deck Torsional Cracking}

The parametric study revealed that some increases in torsional moment in the deck were observed, in particular close to the abutment and pier in the span containing the fracture. In this report, the post-fracture concrete deck torsional demand was compared to be calculated deck torsional capacities (see Table 3.6). The reinforcement details for the bridges included in the study are also summarized in Table 3.6 as this affects the torsional capacity of the deck. It is recognized that the number and the spacing of the deck transverse reinforcement may be different in other bridges.

According to Table 3.6, the torsional demand/ capacity ratio in deck under the Redundancy load combinations were never found to be critical, in other words, maximum demand was always lower that $52 \%$ of the capacity. Therefore, it is concluded that for bridges meeting the criteria (geometry, stiffness, possessing diaphragms torsional cracking does not need be checked under post-fracture behavior. The deck torsional strength was calculated according to ACI 318-14
Section 22.7.6 Torsional Strength (ACI Committee 318, 2014).

\subsubsection{Flexural and Shear Failures Checks for the Deck}

In the parametric study by Korkmaz (2018), it was shown that the intermediate diaphragms transferred the majority of the shear and corresponding moment from the fractured girder to the intact girder. This is due to the fact the intermediate diaphragms possess significantly greater stiffness as compared to the stiffness of the concrete deck. To illustrate this, the stiffness of a given diaphragm arrangement to an effective length of the slab is made and summarized in Table 3.7. The comparison assumes two or three intermediate diaphragms are present within a given exterior span. For the two-diaphragm case, the effective concrete section is assumed to be between the mid-span of the span and the first intermediate diaphragm. (The stiffness of the deck between the abutment and the first diaphragm is not engaged since the relative deflections between girders is very small in this region and in fact, zero at the abutment.) When there were three intermediate diaphragms used for the comparison, the second diaphragm is assumed to be located at the center of the span (as recommended herein). As expected, when the fracture is located near midspan, the load is mostly transferred by the second diaphragm to the intact girder. However, for this comparison, the fracture was also assumed to occur at various locations within the 
TABLE 3.6

WisDOT deck torsional shear demand/capacity ratios and transverse reinforcement details

\begin{tabular}{lccl}
\hline \hline Bridge & Units & $\begin{array}{c}\text { Demand/Capacity } \\
\text { Ratios (Redundancy) }\end{array}$ & $\begin{array}{l}\text { Transverse Reinforcement } \\
\text { Details (Two Layers) }\end{array}$ \\
\hline B05-658 & U1 & 0.40 & $\begin{array}{l}\text { No. } 5 \text { rebars with } 6.5 \text { in. spacing } \\
\text { No. } 5 \text { rebars with } 6.5 \text { in. spacing }\end{array}$ \\
B05-661 & U2 & 0.52 & No. 5 rebar with 7 in. spacing \\
B05-678 & U3 & 0.16 & No. 6 rebar with 7 in. spacing \\
& U4 & 0.47 & No. 6 rebar with 7 in. spacing \\
B05-679 & U5 & 0.46 & No. 6 rebar with 7 in. spacing \\
& U1 & 0.36 & No. 5 rebar with 6.5 in. spacing \\
B40-776 & - & 0.29 & No. 5 rebar with 6.5 in. spacing \\
B40-783 & - & 0.31 & No. 6 rebar with 7 in. spacing \\
B40-786 & U1 & 0.32 & No. 5 rebar with 6 in. spacing \\
B40-834 & U2 & 0.22 & No. 6 rebars with 7 in. spacing \\
B40-837 & - & 0.40 & No. 6 rebars with 7 in. spacing \\
B40-854 & - & 0.39 & No. 6 rebar with 7 in. spacing \\
& U1 & 0.17 & No. 5 rebar with 7 in. spacing \\
B40-856 & U3 & 0.32 & No. 6 rebar with 7 in. spacing \\
B40-868 & U2 & 0.43 & No. 6 rebar with 7 in. spacing \\
\hline
\end{tabular}

span to identify other critical locations. It was found that for the case when three-diaphragms are used, the next critical location is when the fracture is located between the first and second diaphragms. Since the fracture is between diaphragms, the effective deck length (that could participate in load transfer) is half of the distance between the first and second diaphragm. Basically, half the distance between diaphragms.

For all comparisons, a design concrete deck strength of $4 \mathrm{ksi}$ was used as specified for all WisDOT bridges. The elastic modulus ratio between the concrete and steel is about 8 . The transverse span of the deck and the diaphragms is nearly equal and set at the spacing between the girders and therefore can be factored out of the calculations. As is well known, the uncracked stiffness of concrete is much higher than the cracked stiffness. The non-cracked section was used. This was done to demonstrate that even under the best circumstances, i.e., with uncracked concrete, the deck only provides a fraction of the stiffness of the diaphragms.

The results of the comparisons are summarized in Table 3.7. For example, when the number of the diaphragms are equal to three, the deck stiffness is consistently less than $7 \%$ of the diaphragm stiffness and in most cases, less than 5\%. For case when twodiaphragms are used, the stiffness ratios are always less than $10 \%$ except B40-834 in which the deck is about $19 \%$ as stiff as the diaphragm. This is because the first diaphragm was located within the first $25 \%$ of the span length. (As noted above, the recommendations developed herein state that if the first diaphragm needs to be placed at a location less than 0.3L, three intermediate diaphragms need to be used.) Additional analyses were performed and it was found that if three intermediate diaphragms have been used, the ratio would have been equal to $9 \%$. It is also worth noting that as shown in
Table 3.2, the diaphragm flange (which was 16 inches wide) was narrower than minimum exterior span top flange (18 inches wide), which is less than would be recommended herein. If 18 inches was used, the ratio for three intermediate diaphragms would be $7 \%$. If two diaphragms were located at $0.3 \mathrm{~L}$ and $0.7 \mathrm{~L}$, with 18 inch flanges, the ratio would be $9 \%$.

In summary, the diaphragm location and minimum stiffness values recommended herein always ensure that the diaphragm is the main path to transfer the load from the fractured girder to the intact girder and eliminates the need to check flexural and shear failures of the deck as well as shear stud pull-out.

\subsubsection{Items That Do Not Require Specific Checks}

While there are a few items that need be checked to ensure acceptable behavior in the faulted state, there are also a number of items that do not need to be checked when the other recommended criteria or checks are satisfied. As discussed, the full-depth intermediate diaphragms used by WisDOT and pre-fracture dead-load deflection limitations have been found to ensure the following:

- Failure due to overload at a bearing does not occur: As shown in Table 3.8, with the exception of a less than $10 \%$ overload for B05-660, there were no cases where bearings were loaded in excess of the design limit. This level of overload in this one bridge was deemed acceptable. It is noted that this would not be the case if this bridge met the recommendations proposed herein.

- Significant horizontal displacements of girders at bearings does not occur: A shown in Table 3.9, the horizontal displacements are bearings were found to be within acceptable limits. It is noted that the 6.1-inch movement 


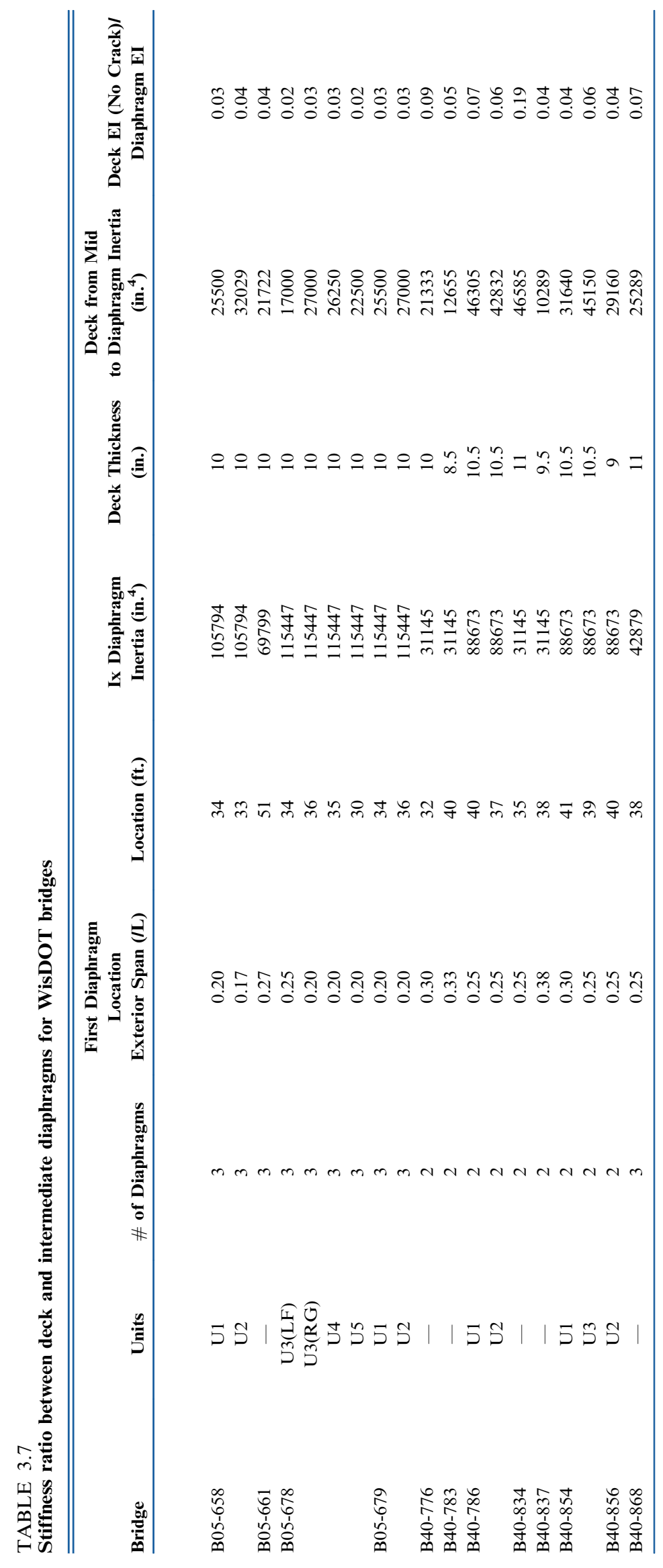


TABLE 3.8

WisDOT support bearing demand/strength

\begin{tabular}{lccc}
\hline \hline Bridge & Units & Pier Bearing Strength (kips) & $\begin{array}{c}\text { Worst-Case Bearing Demands in } \\
\text { Faulted State (kips) }\end{array}$ \\
\hline B05-658 & $\mathrm{U} 1$ & 4480 & 1276 \\
& $\mathrm{U} 2$ & 2450 & 1693 \\
B05-661 & - & 3360 & 1410 \\
B05-678 & $\mathrm{U} 3$ & 3360 & 1710 \\
& $\mathrm{U} 4$ & 2940 & 1693 \\
B05-679 & $\mathrm{U} 5$ & 2940 & 1633 \\
& $\mathrm{U} 1$ & 3360 & 1615 \\
B40-776 & $\mathrm{U} 2$ & 4480 & 1666 \\
B40-783 & - & 1960 & 932 \\
B40-786 & - & 1960 & 725 \\
& $\mathrm{U} 1$ & 2975 & 1693 \\
B40-834 & $\mathrm{U} 2$ & 2975 & 1526 \\
B40-837 & - & 3150 & 913 \\
B40-854 & - & 1592 & 157 \\
& $\mathrm{U} 1$ & 2975 & 169 \\
B40-856 & $\mathrm{U} 3$ & 2975 & 167 \\
B40-868 & $\mathrm{U} 2$ & 2975 & \\
\hline
\end{tabular}

TABLE 3.9

WisDOT maximum horizontal support displacement

\begin{tabular}{lcccc}
\hline \hline Bridge & Units & Span Length (ft.) & $\begin{array}{c}\text { Pre-Fracture Dead Load } \\
\text { Displacement }\end{array}$ & $\begin{array}{c}\text { Post-Fracture Horizontal Support } \\
\text { Displacement (in.) }\end{array}$ \\
\hline B05-658 & U1 & 170 & $\mathrm{~L} / 630$ & 3.45 \\
& $\mathrm{U} 2$ & 199 & $\mathrm{~L} / 415$ & 5.41 \\
B05-661 & - & 187 & $\mathrm{~L} / 375$ & 5.01 \\
B05-678 & $\mathrm{U} 3$ & 180 & $\mathrm{~L} / 545$ & 4.58 \\
& $\mathrm{U} 4$ & 176 & $\mathrm{~L} / 610$ & 4.03 \\
B05-679 & $\mathrm{U} 5$ & 151 & $\mathrm{~L} / 2160$ & 1.53 \\
& $\mathrm{U} 1$ & 170 & $\mathrm{~L} / 850$ & 3.85 \\
B40-776 & $\mathrm{U} 2$ & 181 & $\mathrm{~L} / 670$ & 4.29 \\
B40-783 & - & 105 & $\mathrm{~L} / 365$ & 1.70 \\
B40-786 & - & 119 & $\mathrm{~L} / 410$ & 2.39 \\
& $\mathrm{U} 1$ & 160 & $\mathrm{~L} / 570$ & 3.47 \\
B40-834 & $\mathrm{U} 2$ & 146 & $\mathrm{~L} / 770$ & 2.18 \\
B40-837 & - & 117 & $\mathrm{~L} / 350$ & 1.81 \\
B40-854 & - & 100 & $\mathrm{~L} / 1250$ & $\mathrm{~L} / 850$ \\
& $\mathrm{U} 1$ & 136 & $\mathrm{~L} / 750$ & 0.48 \\
B40-856 & $\mathrm{U} 3$ & 157 & $\mathrm{~L} / 550$ & 2.05 \\
B40-868 & $\mathrm{U} 2$ & 160 & $\mathrm{~L} / 210$ & 1.85 \\
\hline
\end{tabular}

at B05-660 was at a pier and hence, could not "fall off" the bearing. According to AASHTO Guide Specifications (AASHTO, 2018), the change in the maximum vertical deflections of the superstructure should not exceed L/50. The deflection change is defined as a displacement difference between before fracture and after fracture cases, but only under Redundancy II factored dead loads. As a load factor of 1.05 is applied, the limit is taken as L/50. As shown in Table 3.10, the maximum deflection change (L/240 for B40-868) is much lower than specified limit. As shown, the vertical displacements were never found to be critical and not need to be consider in this simplified redundancy check for the twin-tub girder bridges meeting the limitations described in Chapter 3 .

- Failure of lateral braces either does not occur or is not significant: While the specific details are not reported herein, the results of the FEA confirmed there were either no or insignificant failure of secondary cross bracing within the tub girders.

- As stated above, other checks related to excessive deck cracking and shear stud pull-out also need not be checked. 
TABLE 3.10

WisDOT maximum vertical displacement under unfactored dead load in fractured exterior span

\begin{tabular}{|c|c|c|c|c|c|}
\hline Bridge & Units & Span Length (L) (ft.) & $\begin{array}{c}\text { Pre-Fracture Dead Load } \\
\text { Displacements }\end{array}$ & $\begin{array}{l}\text { Post-Fracture Max. } \\
\text { Vertical Displacement } \\
\text { (in.) }\end{array}$ & Vertical Displacements \\
\hline \multirow[t]{2}{*}{ B05-658 } & U1 & 170 & $\mathrm{~L} / 630$ & 3.25 & $\mathrm{~L} / 628$ \\
\hline & U2 & 199 & $\mathrm{~L} / 415$ & 4.14 & L/577 \\
\hline В05-661 & - & 187 & $\mathrm{~L} / 375$ & 3.30 & $\mathrm{~L} / 680$ \\
\hline \multirow[t]{3}{*}{ B05-678 } & U3 & 180 & L/545 & 4.18 & $\mathrm{~L} / 517$ \\
\hline & U4 & 176 & $\mathrm{~L} / 610$ & 3.22 & $\mathrm{~L} / 656$ \\
\hline & U5 & 151 & $\mathrm{~L} / 2160$ & 1.51 & $\mathrm{~L} / 1200$ \\
\hline \multirow[t]{2}{*}{ B05-679 } & U1 & 170 & $\mathrm{~L} / 850$ & 2.54 & $\mathrm{~L} / 803$ \\
\hline & U2 & 181 & $\mathrm{~L} / 670$ & 3.23 & L/672 \\
\hline B40-776 & - & 105 & $\mathrm{~L} / 365$ & 1.50 & $\mathrm{~L} / 840$ \\
\hline B40-783 & - & 119 & $\mathrm{~L} / 410$ & 1.54 & $\mathrm{~L} / 927$ \\
\hline \multirow[t]{2}{*}{ B40-786 } & U1 & 160 & $\mathrm{~L} / 570$ & 2.79 & $\mathrm{~L} / 688$ \\
\hline & $\mathrm{U} 2$ & 146 & $\mathrm{~L} / 770$ & 1.94 & L/903 \\
\hline B40-834 & - & 117 & $\mathrm{~L} / 350$ & 2.20 & $\mathrm{~L} / 638$ \\
\hline B40-837 & - & 100 & $\mathrm{~L} / 1250$ & 0.51 & $\mathrm{~L} / 2353$ \\
\hline \multirow[t]{2}{*}{ B40-854 } & U1 & 136 & $\mathrm{~L} / 850$ & 1.08 & $\mathrm{~L} / 1511$ \\
\hline & U3 & 157 & $\mathrm{~L} / 750$ & 1.20 & $\mathrm{~L} / 1570$ \\
\hline B40-856 & U2 & 160 & $\mathrm{~L} / 550$ & 2.47 & $\mathrm{~L} / 777$ \\
\hline B40-868 & - & 150 & $\mathrm{~L} / 210$ & 7.50 & $\mathrm{~L} / 240$ \\
\hline
\end{tabular}

\section{CONCLUSION}

Today (2019), all twin-tub girder bridges are automatically classified as having FCMs; hence, twin-tub girder bridges are subjected to very expensive hands-on field inspection every two years. On the other hand, Purdue University researchers showed in the recent projects (Connor et al., 2018; Connor \& Korkmaz, 2016; Korkmaz et al., 2018) that some twin-tub-girder bridges were able to be classified as redundant structures, since they possess significant reserve capacity even when one girder is completely severed. These studies were reviewed by Wisconsin DOT and the FHWA. These bridges are no longer classified as having FCMs, but rather has been classified as having SRMs.

This report explained the simplified guideline and design checks to ensure new designed twin-tub girder bridges will meet the requirements of AASHTO Guide Specifications (AASHTO, 2018) without the need for full non-linear FEA. The simple guidance in this project is believed to be sufficient to classify continuous composite twin-tub girder bridges which have similar features with WisDOT bridges described as having SRMs.

The methodology requires that future twin-tub girder bridges need to have intermediate diaphragms to be redundant. The full-depth intermediate diaphragms used by WisDOT also appear to reduce the likelihood of shear stud failures, bottom flange buckling at/close to support, deck and parapet crushing, deck reinforcement yielding, lateral brace failing, and torsional buckling in the intact girders. These diaphragms were shown to be very effective in transferring load in the faulted condition and significantly contributed to the excellent system performance of the bridges in the
Wisconsin inventory. Although some of the WisDOT bridges exhibited minor plasticity in the flanges of the intermediate diaphragms and a few shear stud failures, the level of plasticity is localized and number of failed studs is not significant. Properly designed and detailed studs have also been shown to be critical in the postfracture performance of twin-tub girder bridges. Although the diaphragm typically used by WisDOT generally prevent issues with shear stud concrete breakout, specific guidance on how to best detail and layout shears studs were studied and explained in the report. In addition, the locations of bottom flange section changes in a span and thickness changes are limited to avoid this failure in any location of the span. The unfaulted positive moment demand/capacity ratio was determined for the Strength I load combination in order to not have any bottom flange buckling, deck and parapet crushing or reinforcement yielding in postfracture condition.

The proposed ballot ready specification language provided in Appendix A presents a method on how twin-tub girder bridges can be easily and reliably designed as redundant structures. With the attached Appendix A. Proposed Specifications and Appendix B. Design Example, an engineer can simply design a new twin-tub girder bridge as redundant structure without the need for advanced non-linear FEA. If the bridge does not meet the criteria defined above, the user should follow The AASHTO Guide Specifications for Analysis and Identification of Fracture Critical Members and System Redundant Members, 1st Edition (AASHTO, 2018). The overall behavior may be similar for I-girder bridges. In the future projects, the similar methodology can be developed for I-girder bridges which have fracture critical members. 


\section{REFERENCES}

AASHTO. (2018). AASHTO guide specifications for analysis and identification of fracture critical members and system redundant members. American Association of State Highway and Transportation Officials.

AASHTO/AWS. (2020). Bridge welding code (D1.5M/D1.5). https://pubs.aws.org/p/2014/aashtoaws-d15md152020bridge-welding-code

AASHTO. (2020). LRFD bridge design specification (9th ed.). American Association of State Highway and Transportation Officials. https://aashtojournal.org/2020/05/08/ aashto-issues-updated-lrfd-bridge-design-guide/

ACI Committee 318. (2014). Building code requirements for structural concrete and commentary (ACI 318-14). American Concrete Institute. http://aghababaie.usc.ac.ir/files/1506505 203365.pdf

Barnard, T., Hovell, C. G., Sutton, P. J., Mouras, J. M., Neuman, B. J., Samaras, V. A., Kim, J., Williamson, E. B., \& Frank, K. H. (2010, February). Modeling the response of fracture critical steel box-girder bridges (Report No. FHWA/TX-10/9-5498-1). Texas Department of Transportation. https://ctr.utexas.edu/wp-content/uploads/pubs/9_ 5498_1.pdf

Connor, R. J., Bonachera Martín, F. J., Varma, A., Lai, Z., \& Korkmaz, C. (2018). Fracture-critical system analysis for steel bridges (NCHRP Research Report 883). National Academies Press. https://doi.org/10.17226/25230
Connor, R. J., Dexter, R., \& Mahmoud, H. (2005). Inspection and management of bridges with fracture-critical details (NCHRP Synthesis 354). National Academy Press. http:// onlinepubs.trb.org/onlinepubs/nchrp/nchrp_syn_354.pdf

Connor, R. J., \& Korkmaz, C. (2016). Evaluation of the fracture critical status of ramp TH over interstate 43/894 in Milwaukee, Wisconsin. Purdue University S-BRITE Center

Inspection Frequency, Title 23 C.F.R. \$650.311 (2013). https://idx?SID =28658b4f89c30af7a4b1de9e7515e5f0\& $\mathrm{mc}=$ true\&node $=\mathrm{se} 23.1 .650 \_1311 \& \mathrm{rgn}=\operatorname{div} 8$

Korkmaz, C. (2018). Evaluation of redundancy in composite twin-tub-girder bridges with finite element analysis [Doctoral dissertation, Purdue University]. https://docs.lib.purdue. edu/dissertations/AAI10792733/

Korkmaz, C., Connor, R. J., Bonachera Martín, F. J., \& Campbell, L. E. (2018). Analytical evaluation after-fracture system performance of typical steel twin-tub girder bridges in the State of Wisconsin. Purdue University S-BRITE Center.

Mouras, J. M., Sutton, J. P., Frank, K. H., \& Williamson, E. B. (2008, October). The tensile capacity of welded shear studs (Research Report No. FHWA/TX-09/9-5498-2). Center for Transportation Research University of Texas at Austin. https://ctr.utexas.edu/wp-content/uploads/pubs/ 9_5498_2.pdf

Regulatory Information, Title 23 C.F.R. 1650.305 (2009). https://www.govinfo.gov/app/details/CFR-2009-title23vol1/CFR-2009-title23-vol1-sec650-305 


\section{APPENDICES}

Appendix A. Proposed Specifications for Designing SRMs in Composite Continuous Twin-Tub Girder Bridges

Appendix B. Design Example 


\section{APPENDIX A. PROPOSED SPECIFICATIONS FOR DESIGNING SRMS IN COMPOSITE CONTINUOUS TWIN-TUB GIRDER BRIDGES}

\section{Foreword}

LRFD Bridge Design Specifications (BDS) (AASHTO, 2020) defines "Fracture Critical Members" (FCMs) as that the fracture of any of the FCMs is assumed to result in complete catastrophic failure or significant loss of serviceability. The decision to define members as FCMs has often been made without considering actual system redundancy or performance of the structure. According to the concepts associated with the term "Fracture Critical," all two-girder bridges (including twin-tub-girder bridges) are classified as having FCMs due to their perceived lack of load path redundancy; hence, every two years twin-tub girder bridges undergo very expensive hands-on field inspections.

Prior to the development of the specifications contained herein, no such simple guidance currently exists to design continuous twin-tub girder bridges as having SRMs. However, recent works performed by Purdue University researchers including Ramp TH over Interstate 43/894 in Milwaukee (Connor \& Korkmaz, 2016) and Analytical Evaluation of the Post-fracture System Performance of Typical Steel Twin-Tub Girder Bridges in the State of Wisconsin Phase I (Korkmaz et al., 2018) showed that twin-tub girder bridges often possess significant reserve capacity even when one girder is completely severed. The bridges analyzed in these references were evaluated using the system analysis procedures defined in the AASHTO Guide Specifications for Analysis and Identification of Fracture Critical Members and System Redundant Members (AASHTO, 2018), and full 3D non-linear dynamic finite element analysis (FEA) was required to complete the evaluations The twin-tub girder bridges which have multiple full-depth and fullwidth intermediate diaphragms, certain geometric details, and continuous spans classified as having SRMs.

This simplified guidance was developed to ensure newly designed twin-tub girder bridges will meet all the requirements defined in this AASHTO Guide Specifications without performing indepth FEA. How to design and detail such bridges in order to meet the criteria and satisfy minimum strength and serviceability performance requirements and the geometric limitations and configurations to which the proposed criteria apply were explained. With this guidance, it becomes 
possible to design future twin-tub girders can be automatically classified as having SRMs without the necessity of explicitly modeling fracture in a FEA.

The commentary directs attention to other documents that provide suggestions for carrying out the requirements and the intent of this guidance. the commentary is not intended to provide every detail as to the development of this guidance, nor is it intended to provide a detailed summary of the studies and research data reviewed in formulating the provisions of this guidance. The reader is encouraged to review the final report for A Simplified Approach to Design Composite Continuous Twin-tub Girder Bridges as Redundant Structures, which include more complete details and background related to the development of these guidance. 


\section{Definitions}

Component (of a primary $=\mathrm{A}$ portion of a (primary) member with a specific design member) function; for example, the flange of a girder, the web of a girder, a plate in an axial member.

\section{Fracture Critical Member}

(FCM)

Member Failure (Failed Member)

Faulted State

Redundancy

System Redundant Member (SRM)
$=\mathrm{A}$ steel primary member or portion thereof subject to tension whose failure would probably cause a portion of or the entire bridge to collapse.

$=$ Inability of a particular cross-section of a FCM to carry any load. In these provisions, this state is introduced via element deletion or material softening. This results in the faulted state.

$=$ State of the bridge with an assumed failed FCM, as opposed to the unfaulted state.

$=$ Ability of a structure to provide an alternate resistance mechanism after the failure of a primary member.

$=$ A steel primary member or portion thereof subject to tension for which the redundancy is not known by engineering judgment, but which is demonstrated to have redundancy through a refined analysis. SRMs must be designated on the contract documents to be fabricated according to Clause 12 of the AASHTO/AWS D1.5M/D1.5 Bridge Welding Code (AASHTO/AWS, 2015). A SRM need not be subject to the inspection protocols for a FCM as described in 23 CFR 650.305 (Regulatory Information, 2009). 


\section{Notation}

$\boldsymbol{D}_{\boldsymbol{F}} \quad=$ Pre-fracture dead load displacement (feet) of the fractured span.

$\boldsymbol{L}=$ Each span length (feet).

$\boldsymbol{L}_{\boldsymbol{F}} \quad=$ Span length of fractured span (feet). 


\subsubsection{Special Provisions for Twin-tub Girder Bridges}

\section{0-General}

The provisions contained in these articles shall be used when it is desired to design continuous twin-tub girder bridges as having System Redundant Members (SRMs). These provisions are not applicable to single span bridges.

\section{1-Approach}

The following steps shall be followed in the assessment of the redundancy using these provisions:

- Perform the Screening according to the provisions specified in Article 2.

- If the bridge satisfies Article 2, the design shall be evaluated further as specified in Articles 3.

\section{SUGGESTED NEW ARTICLE WHERE THESE PROVISIONS WOULD BE INCORPORATED INTO THE AASHTO LRFD BDS.}

\section{C1.0}

The provisions described herein are applicable to newly designed but yet to be constructed continuous twin-tub girder bridges.

These provisions are primarily based on the work reported in A Simplified Approach to Design Composite Continuous Twin-tub Girder Bridges as Redundant Structures. Newly designed twin-tub girder bridges that satisfy these provisions will meet all the requirements defined in the AASHTO Guide Specifications for Analysis and Identification of Fracture Critical Members and System Redundant Members (AASHTO Guide, 2018) without performing in-depth FEA. Members satisfying these provisions may also be classified as System Redundant Members (SRMs) and need not be subject to the inspection protocols for FCMs as described in 23 CFR 650.305 (Regulatory Information, 2009).

Traditional simple elastic structural analysis models and hand calculations are sufficient to fulfil all the steps defined.

The damage scenario that was considered included complete full-depth fracture (including the top flanges) of one of the tub girders. The load model used were based on the Redundancy I and Redundancy II load combinations defined in the AASHTO Guide (2018).

\section{C1.1}

The Engineer may choose to follow the provisions described in Article 2 and Article 3 in a different order than that shown in Figure A.1. However, the process shown in Figure A.1 is usually the most efficient. 


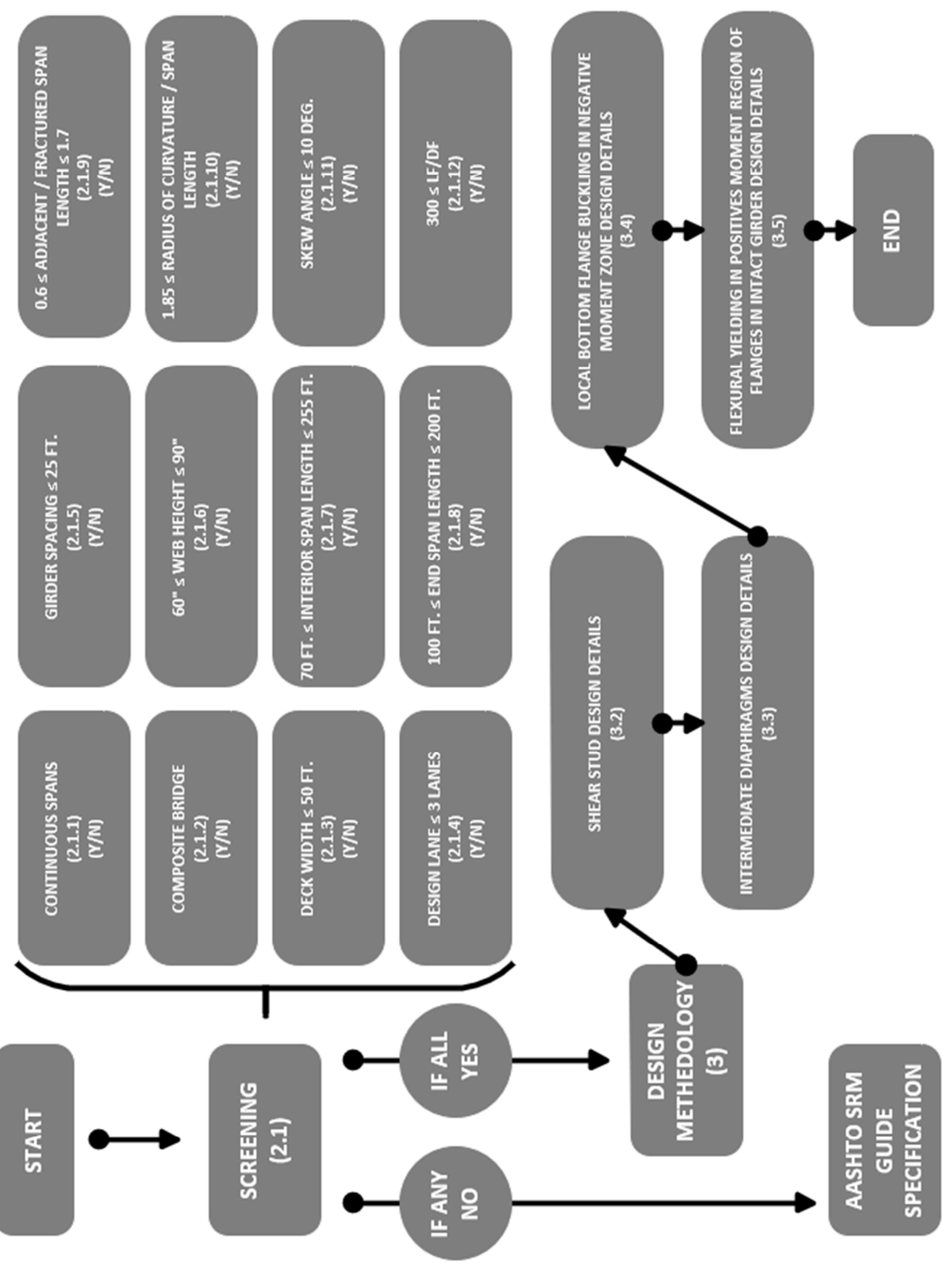

Figure A.1 Flowchart describing all guideline steps. 


\section{0-Screening}

Prior to analyzing a structure according to the provisions specified in Article 3, the requirements of Article 2.1 shall be satisfied.

\section{1-Screening Criteria}

The provisions shall be satisfied in order to use the provisions contained herein.

2.1.1 There shall be a minimum of two or more continuous spans.

2.1.2 Composite section with shear stud details as defined in Article 3.2.

2.1.3 Maximum out-to-out deck width $\leq 50$ feet;

2.1.4 The maximum number of design lanes shall be limited to three.

2.1.5 Maximum center-to-center girder spacing $\leq$ 25 feet.

2.1.6 60 inches $\leq$ web depth $\leq 90$ inches.

2.1.7 70 feet $\leq$ interior span length $\leq 250$ feet.

2.1.8 100 feet $\leq$ exterior span length $\leq 200$ feet

2.1.9 The ratio of the unfractured adjacent span length to the fractured span length with in 0.6 and 1.7 .

2.1.10 The ratio of the radius of curvature to the longest span length no less than 1.85 .

2.1.11 Skew angle no more than 10 degree

2.1.12 Maximum dead load displacement at both interior and exterior spans $\left(\mathrm{L}_{\mathrm{F}} / \mathrm{D}_{\mathrm{F}}\right)$ over corresponding span length less than 300 .

Where:

$\mathrm{L}_{\mathrm{f}}$ is the span length of fractured span (ft)

$\mathrm{D}_{\mathrm{f}}$ is the pre-fracture dead load displacement $(\mathrm{ft})$ of the fractured span
C2.0

The rationale for the screening process specified in this article is to ensure that this guidance is not applied to bridges for which either the system or a particular member assumed to remain intact may demonstrate unacceptable performance or reliability. For example, when satisfied, excessive shear stud pull-out failures would not be expected to occur in the faulted state under the Redundancy load combinations.

The user must recognize that while a structure may not comply with the simple screening and evaluation provisions herein, this does not necessarily mean it would not meet the AASHTO Guide (2018) since they were developed to be reasonably conservative and very simple to apply. In such cases, 3-D detailed FEA may show that the structure has sufficient reserve strength can be demonstrated to satisfy the requirements of the AASHTO Guide (2018). For such cases, it is recommended to follow the approach defined in the AASHTO Guide (2018) and NCHRP Report 883 (Connor et al., 2018).

\section{C2.1}

Geometric limitations were developed to ensure that post-fracture behavior is predicted accurately and to ensure there are no unexpected failure modes. These limitations are based on the wide range of types and geometry of bridges analyzed in the study of Analytical Evaluation of the Post-fracture System Performance of Typical Steel Twin-tub Girder Bridges in the State of Wisconsin Phase I (Korkmaz et al., 2018). The results of that and other research were used to develop the simplified methodology summarized in A Simplified Approach to Design Composite Continuous Twin-tub Girder Bridges as Redundant Structures. The requirements were developed to be (1) easy to use and (2) ensure behavior that satisfies the Guide Specifications (AASHTO, 2018) in the faulted without the need for detailed nonlinear FEA.

The criteria in Articles 2.1.1 through 2.1.12 were developed based on the parameters studied during the development of these criteria.

The ratio of the length of the span that is assumed to have fractured to the pre-fracture dead load displacement of that span has been found to be a strong predictor in estimating the post-fracture behavior. In effect, it is an indicator of the overall flexibility of the structure in the faulted state. If the displacement is high compared to span length, it is likely the bridge will undergo moderate to significant inelastic behavior in the faulted state. In other words, if this ratio is lower than the specified limit, these provisions may not be able to accurately estimate the behavior because of the occurrence of significant local plasticity in some cases. It should be noted here, positive 
displacements are in the downward direction, whereas negative displacements show upward deflections. If the span length where the fracture is assumed to occur over the maximum dead load displacement at mid-span $\left(\mathrm{L}_{\mathrm{F}} / \mathrm{D}_{\mathrm{F}}\right)$ is less than 300 , this methodology cannot be applied as the overall structure is too flexible and excessive inelastic behavior may occur. 


\section{0-Design Methodology}

\section{1-General}

The requirements specified herein shall be considered applicable to steel bridges that satisfy Article 2.1.

The following twin-tub girder members and/or components shall be designed as a minimum to satisfy:

1. the shear stud provisions specified in article 3.2;

2. the provisions for intermediate diaphragms specified in article 3.3;

3. the bottom flange buckling resistance provisions specified in Article 3.3;

4. the maximum positive moment flexural resistance specified in Article 3.4.

\section{2-Shear Stud Design Details}

\section{Basic Geometric Requirements}

1. Shear stud diameter shall be a minimum of $7 / 8$ inches.

2. Minimum edge distance between the outermost stud and edge of haunch shall be a minimum 1.5 inches.

3. Shear studs shall extend a minimum of 2 inches above the bottom layer of reinforcement.

\section{Spacing Details}

Shear studs shall be used through the entire girder.

When two shear studs are placed transversely.

1. The maximum longitudinal spacing between studs shall not exceed three times the effective stud height.

2. The maximum longitudinal spacing between studs shall not exceed 14 inches.

\section{C3.1}

The requirements of Article 3 were developed according to detailed FE analysis results, section details, and demand/capacity ratios of 18 multi-span twin-tub girder bridge units (in total 2.4 miles and 70 spans) that were studied in detail using the procedures outlined in the AASHTO Guide (2018) as performed by (Korkmaz et al., 2018). The FE analysis results were used to obtain postfracture demand/capacity ratios under the Redundancy load combinations and compared to the demand/capacity ratios under the familiar Strength I load combination. Many ratios using the Redundancy load factors were equal to, insignificantly higher, or in most cases less than ratios for the Strength I limit state in the unfaulted state. The study revealed that when the requirements of Article 3 are satisfied, the following failure modes need not be considered under the Redundancy load factors in the faulted state:

- web shear buckling;

- deck related failure modes due to flexure, shear and torsion;

- $\quad$ support bearing failure due to excessive reactions and excessive horizontal displacements;

- excessive vertical displacement in the faulted state;

- brace failures.

However, some of the failure modes that were evaluated at times were shown to have higher demand/capacity ratios using the Redundancy load factors in the faulted states as compared to the Strength I in the unfaulted state. To ensure these failure modes never exist in post-fracture behavior, the requirements of Article 3 were developed.

\section{C3.2}

The tensile and shear behavior of shear studs is critical in the load transfer between the steel members and the concrete slab in composite steel bridges as they help provide additional load paths after the failure of a primary steel member. The superior ability of composite steel bridges to transfer load was shown by Barnard et al. (2010), who performed full-scale experiments in a simple span UT twin-tub girder bridge that underwent failure of the bottom flange and web of one of the tub girders. Therefore, given their essential role in composite action, shear studs need to be designed properly to make to the bridge stay in composite behavior in the post-fracture performance of twin-tub girder bridges. 
When three shear studs are placed transversely.

1. The maximum longitudinal spacing between studs shall not be more than three times the effective stud height.

2. The maximum longitudinal spacing between studs shall not be more 22 inches.

\section{3-Intermediate Diaphragm Design Details}

Diaphragms shall be placed within every span and be full-depth and full-width (i.e., both internal and external sections shall be used between the girders).

The intermediate diaphragms of interior spans shall possess the same cross-section as used in the exterior span diaphragms.

\subsubsection{Diaphragm Plate Size Requirements}

1. The top and bottom flange of all the diaphragms shall be equal to the smallest top flange used in the longer exterior span outside girder.

2. Web sections of the diaphragms shall be as close as practical to the minimum web section utilized in the longer exterior span outside girder.

3. The connections shall be designed using normal AASHTO procedures.

\subsubsection{Number and Location of the Diaphragms}

The number and location of diaphragms differs based on whether an exterior span or interior span is being considered.

\section{Exterior Spans}

When the unfactored dead load deflection is less than or equal to $\mathrm{L} / 500$ at $30 \%$ of the span length $(0.3 \mathrm{~L})$ from the abutment.

1. Two intermediate diaphragms shall be used.

2. The first diaphragm shall be placed between $0.3 \mathrm{~L}$ and $0.4 \mathrm{~L}$ and shall not be placed beyond the location where the displacement is equivalent to $\mathrm{L} / 500$.

3. The second diaphragm shall be placed symmetrically within the same span.

When the unfactored dead load deflection is greater than $\mathrm{L} / 500$ at $30 \%$ of the span length $(0.3 \mathrm{~L})$ from the abutment.

1. Three intermediate diaphragms shall be used.

2. The first diaphragm shall be placed as close as practical to the location where the deflection is $\mathrm{L} / 500$.

3. The second diaphragm shall be placed as close as practical to mid-span.

\section{C3.3}

\section{C3.3.1}

The required size, location and number of the intermediate diaphragms is also based on the details observed in this study. Obviously, intermediate diaphragms are required to be designed to guarantee adequate load distribution between girders in the faulted state. The diaphragms between the girders only need to have top flanges whereas external diaphragm requires to include both bottom and top flanges. It is recommended to provide shear studs on the top flanges of the diaphragms to increase stiffness.

\section{C3.3.2}

In this study, it was found that the placement and quantity of the intermediate diaphragms can be easily determined in relation to the pre-fracture dead load deflection.

The optimal number and location of the diaphragms in a span were developed to (1) best distribute the loads between the intact and fractured spans; (2) reduce the post-fracture moment at the pier; and (3) avoid significant damage to the deck, including stud pull-out. The best responses were observed when the first diaphragm is located at about $30 \%$ of the span length and the second diaphragm is placed symmetrically within the span. 
4. The third diaphragm shall be placed as close as practical to be symmetrical with the first diaphragm within the span.

Interior Spans

1. Two intermediate diaphragms shall be used in all cases.

2. The diaphragms shall be placed as close as is practical to the third points of the span.

\section{4-Local Bottom Flange Buckling in the Negative Moment Regions}

The maximum demand/capacity ratio in the negative moment region shall not be greater than 0.7 under the Strength I load combination in the region between $0.2 \mathrm{~L}$ and $0.3 \mathrm{~L}$ away from a pier in the unfaulted state.

\section{5-Flexural Yielding in Positives Moment Region of Flanges in Intact Girder Design Details \\ The maximum demand/capacity ratio in the composite positive moment region of each span shall not be greater than 0.8 under the Strength I load combination in the unfaulted state.}

\section{C3.4}

This study explains that there is no need to check negative moment buckling in the faulted state in the region between the pier and for a distance of up to $0.2 \mathrm{~L}$ away from the pier as it was found all of the demand/capacity ratios for the Strength I load combination are generally higher than those produced in the faulted state using the Redundancy load combinations. The only area of concern was in the region between $0.2 \mathrm{~L}$ and $0.3 \mathrm{~L}$ for a few bridges when flange transitions were introduced within this region. This criterion is intended to prevent the possibility of buckling in this region due to the placement of flange transitions. No added checks were found to be needed at distances greater than $0.3 \mathrm{~L}$ away from a pier as the typical sections utilized to satisfy the Strength I requirements were sufficient in the faulted state.

\section{C3.5}

It has been found that the when demand/capacity ratio in the exterior girder under the Strength I load combination in the unfaulted state is greater than 0.8 , the intact girder may exceed the elastic moment capacity at mid-span in the faulted state. A considerable amount of plasticity in the positive moment region will result in significantly more moment being redistributed to the girders in the negative moment region close to the pier. To ensure unacceptably high levels of inelastic behavior in the positive moment regions does not occur, this limit was introduced. 


\section{APPENDIX B. DESIGN EXAMPLE}

A continuous three span twin-tub girder bridge will be evaluated and modified as needed using the methodology described in the proposed guide specification in Appendix A. In this example, the "baseline" bridge has been designed to satisfy the AASHTO LRFD Bridge Design Specifications. All required strength and service criteria in the AASHTO LRFD Bridge Design Specifications were satisfied in the initial design. First, attributes described in the screening criteria will be evaluated. Second, the proposed design methodology will be applied to ensure the primary girders may be classified as SRMs instead of FCMs.

The structure has three spans measuring 111-111-119 feet long, and it is uniformly curved with a radius of 220.5 feet (measured from bridge centerline). The two trapezoidal box girders have bottom flanges that are 7.5-feet wide, 60-inch high webs and 18-inch wide top flanges throughout all spans; with variable plate thicknesses. The reinforced concrete slab is approximately 32 feet wide between outer exterior edges of the concrete barriers and is fully composite with the girders. The end supports are multi-rotational unidirectional bearings, and the supports over the pier are multi-rotational fixed bearings.

Table B.1 provides details related to the geometry and material properties associated with the structure. 
Table B.1 The bridge geometry and material properties

\begin{tabular}{|c|c|}
\hline \multicolumn{2}{|c|}{ Bridge Details } \\
\hline Bridge Name & Example Bridge \\
\hline Radius of Curvature & $220.5 \mathrm{ft}$. (measured from bridge centerline) \\
\hline Span Lengths & $111.0-111.0-119.0 \mathrm{ft}$. \\
\hline \multicolumn{2}{|c|}{ Girder Details } \\
\hline Girder Steel & ASTM A709 HPS 50WF \\
\hline $\begin{array}{l}\text { Box Girder Width (from the centers of } \\
\text { interior top-flange to the center of } \\
\text { exterior top-flange) }\end{array}$ & $7.5 \mathrm{ft}$. \\
\hline $\begin{array}{l}\text { Girders Spacing (from the centers of the } \\
\text { girders' bottom flanges) }\end{array}$ & $16.0 \mathrm{ft}$ \\
\hline Top Flange & $\begin{array}{l}18.0 \text {-in. wide } \\
\text { Varies, } 0.75 \text {-in. to } 1.125 \text {-in. thick }\end{array}$ \\
\hline Web & $\begin{array}{l}\text { 60-in. high } \\
0.625 \text {-in. thick }\end{array}$ \\
\hline Bottom Flange & $\begin{array}{l}63 \text {-in. wide } \\
\text { Varies, } 0.75 \text {-in. to } 1.25 \text {-in. thick }\end{array}$ \\
\hline Internal Cross Frames & $2 \mathrm{~L} 6 \times 4 \times 1 / 2(\mathrm{Top}), 2 \mathrm{~L} 6 \times 3-1 / 2 \times 3 / 8$ (Inclined) \\
\hline Strut Braces & $2 \mathrm{~L} 6 \times 4 \times 1 / 2$ \\
\hline Lateral Braces & WT7 $\times 30.5, \mathrm{WT} 8 \times 33.5, \mathrm{WT} 8 \times 38.5$ \\
\hline $\begin{array}{l}\text { Longitudinal Stiffeners on Bottom } \\
\text { Flanges }\end{array}$ & - \\
\hline \multicolumn{2}{|c|}{ Deck Details } \\
\hline Concrete Material Strength & $4 \mathrm{ksi}(\mathrm{HPC})$ \\
\hline Composite Deck & $\begin{array}{l}\text { 31.896-ft. wide, } 8.5 \text {-in. thick } \\
\text { 3-in. haunch thick }\end{array}$ \\
\hline Transverse Reinforcement & No. 5 rebar with 6 -in. spacing \\
\hline Longitudinal Reinforcement & No. $4 \&$ No. 6 rebar with 7 -in. spacing \\
\hline Overhang Reinforcement & No. 5 rebar with 6-in. spacing \\
\hline Shear Studs & $\begin{array}{l}\text { 7-in. height. Longitudinal spacing is } 12 \text { in. } \\
\text { Three shear studs spaced equally in the } \\
\text { transverse direction }\end{array}$ \\
\hline Parapet Type & 32SS (Interior)-42SS (Exterior) \\
\hline \multicolumn{2}{|c|}{ Load Details } \\
\hline Maximum Number of Design Lane & Two lanes of HL-93 traffic \\
\hline Future Wearing Surface & $20 \mathrm{lb} / \mathrm{ft}^{2}$ \\
\hline $\begin{array}{l}\text { Maximum Dead Load Displacement } \\
\text { (before fracture) }\end{array}$ & $\begin{array}{l}\text { L/485 (Span 1) Span } 2 \text { deflected upward, } \\
\text { L/410 (Span 3) }\end{array}$ \\
\hline
\end{tabular}




\section{B.1 Screening Criteria (Article 2)}

A review of Table B.1 indicates this bridge satisfies all the screening criteria specified in Article 2.1. Specifically:

1. The bridge has three continuous spans thereby satisfying the criterion defined in Article 2.1.1 "there shall be a minimum of two or more continuous spans."

2. The reinforced concrete slab is fully composite with the girders through the use of shear studs. This satisfies the criterion defined in Article 2.1.2 "composite section with shear studs."

3. The reinforced concrete slab is approximately 32 feet wide between outer exterior edges of concrete barriers that satisfies the criterion defined in Article 2.1.3 that "maximum out-toout deck width $\leq 50$ feet."

4. The maximum number of design lanes is two thereby satisfying the criterion defined in Article 2.1.4 "the maximum number of design lanes no more than three."

5. The girder spacing (measured as the center to center distance between bottom flanges) is 16 feet wide. This satisfies the criterion defined in Article 2.1.5 "maximum center-to-center girder spacing $\leq 25$ feet."

6. Each of the trapezoidal box girders have 60 inch deep webs thereby that satisfying the criterion defined in Article 2.1.6 "60 inches $\leq$ web depth $\leq 90$ inches."

7. The interior span is 111 feet length and hence satisfies the criterion defined in Article 2.1.7 "70 feet $\leq$ interior span length $\leq 250$ feet."

8. The exterior or exterior spans are 111 and 119 feet length thereby satisfying the criterion defined in Article 2.1.8 "100 feet $\leq$ exterior span length $\leq 200$ feet."

9. The ratio of the unfractured adjacent span length to the fractured span lengths are between 0.93 and 1.07. This satisfies the criterion defined in Article 2.1.9 "the ratio of the unfractured adjacent span length to the fractured span length with in 0.6 and 1.7." In this three span bridge this is 111 feet / 119 feet to 119 feet / 111 feet.

10. The ratio of the radius of curvature to the longest span length is 1.85 that satisfies the criterion defined in Article 2.1.10 "the ratio of the radius of curvature to the longest span length no less than 1.85". This is calculated as $220.5 \mathrm{feet} / 119 \mathrm{feet}=1.85$.

11. The bridge skew angle is 0 degrees and satisfies the criteria defined in Article 2.1.11 "skew angle no more than 10 degrees." 
12. The maximum dead load displacement at both interior and exterior spans $\left(\mathrm{L}_{\mathrm{F}} / \mathrm{D}_{\mathrm{F}}\right)$ dived by the corresponding span length are $\mathrm{L}_{\mathrm{F}} / 485$ (1st span) and $\mathrm{L}_{\mathrm{F}} / 410$ (3rd span) which satisfies the criterion defined in Article 2.1.12 which states "the maximum dead load displacement at both interior and exterior spans $\left(L_{F} / D_{F}\right)$ over corresponding span length less than $300 . "$

Since this bridge satisfies all the screening criteria specified in Article 2.1 it is a candidate for using the simplified approach to determine if the girders can be classified as SRMs. The screening assessment is also shown graphically in Figure B.1.

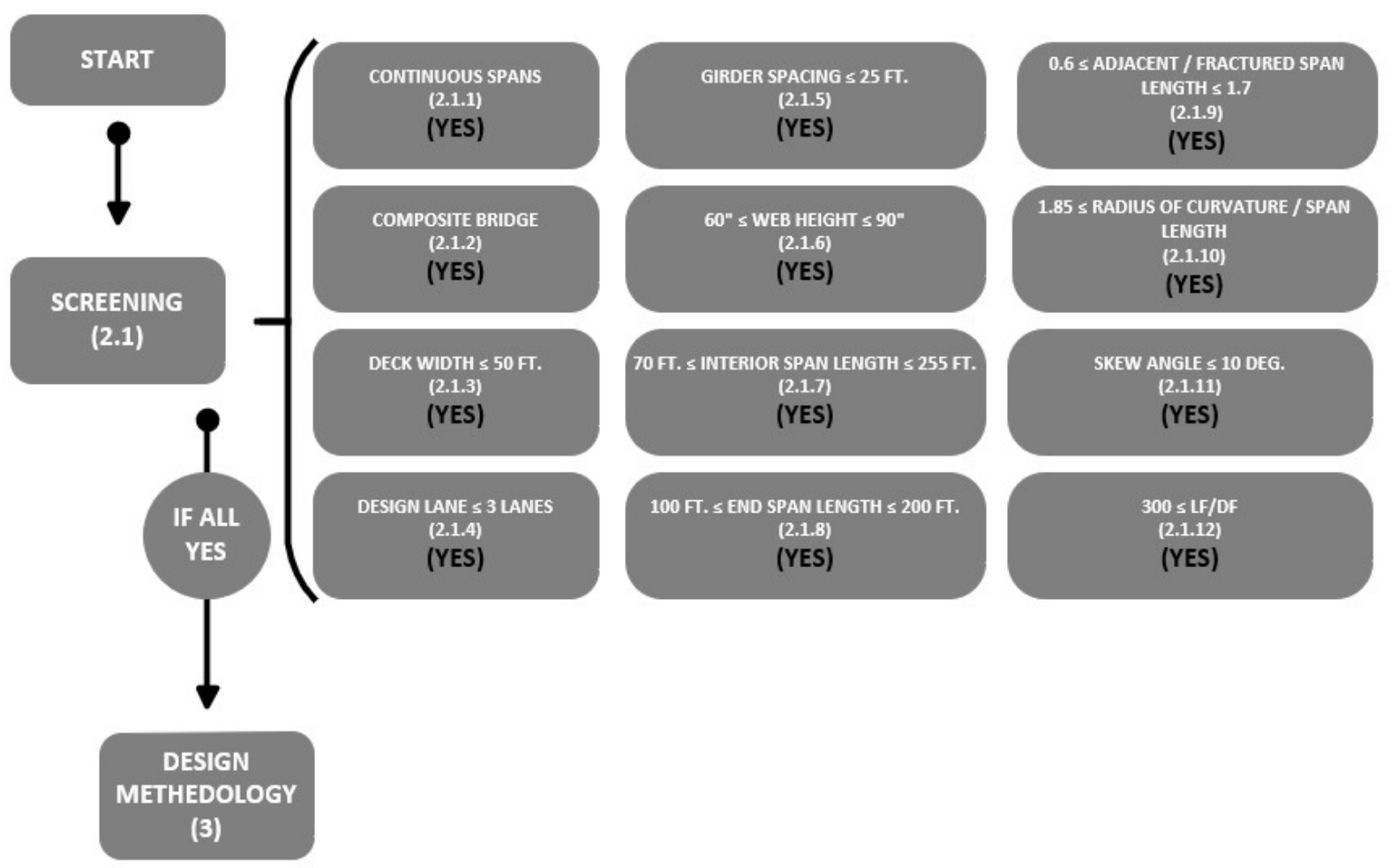

Figure B.1 Screening criteria flowchart. 


\section{B.3 Design Methodology (Article 3)}

\section{B.3.1 Shear Stud Design Details (Article 3.2)}

Basic Geometric Requirements:

During the original design, it was determined that three $7 / 8$ inch diameter shear studs spaced transversely were needed in order to meet the strength and service limit states required by the AASHTO LRFD Bridge Design Specification. These shear studs were detailed by the designer as follows:

(1) 7/8-inch diameter shear studs were used.

a. This satisfies the minimum specified limit of $7 / 8$ inch.

(2) The distance between outermost stud and edge of the haunch was set at 2 inches.

a. This satisfies the minimum specified limit of $1.5 \mathrm{inch}$.

(3) The shear studs were detailed to extend 2.25 inches above the bottom layer of reinforcement

a. This satisfies the minimum specified limit of 2.0 inches.

The distance that the shear studs extend above the bottom layer of reinforcement calculated as follows:

Shear stud effective height + minimum top flange thickness - (clearance distance + rebar diameter + haunch thickness $)=2.25$ inches

- The required shear stud effective height was found to be 6.625 inches based on the geometry of the deck and haunch.

- The clear distance between bottom reinforcement to the bottom surface of the deck is 1.5 inch.

- All reinforcement in the lower matt were \#5 bars (diameter is 0.625 inch).

- The maximum haunch thickness (distance between bottom of top flange to underside of slab) is conservatively set at 3 inches.

- Minimum top flange thickness is 0.75 inch.

\section{Spacing Details of Shear Studs:}

Based on the original design the longitudinal spacing between studs was to 12 inches. This is less than the maximum permitted spacing of three times the smaller of effective stud height $(3 \times 6.625$ $=19.875$ or 22 inches. Hence, the longitudinal spacing is also acceptable. 


\section{B.3.2 Intermediate Diaphragm Design Details (Article 3.3)}

The proposed specifications require that diaphragms be placed within every span and be full-depth and full-width (i.e., both internal and external sections shall be used between the girders). The requirements also stipulate that the intermediate diaphragms of interior spans possess the same cross-section as used in the exterior span diaphragms. The specific provisions are included in Article 3.3.

\section{Required Diaphragm Plate Sizes:}

1. A review of the original design plans indicates that smallest top flange used in the longer exterior span of the outside girder is 18 inches wide and 0.75 inches thick. In the original design, the flanges of the diaphragms were 16 inches wide and 0.75 inches thick. The diaphragms were located at the 1/3 points of the span. However, per Article 3.3.1(1), the top and bottom flange of all the diaphragms shall be set equal to the smallest top flange used in the longer exterior span outside girder. Hence, the flanges of all diaphragms will be set at 18 inches $\times 0.75$ inches.

2. A review of the original design plans indicates the minimum web section used in the longest outside girder in an exterior span is 60 inch high and 0.625 inch thick. In the original design, the flanges of the webs of the diaphragms were 60 inches high and 0.5 inches thick. However, per Article 3.3.1(2), the diaphragm webs shall be equal to minimum web section utilized in the longer exterior span outside girder. Hence, the web depth will be set at 60 inches and the thickness will be set at 0.625 inches.

3. The connections were designed using normal AASHTO procedures.

\section{Number and Location of the Diaphragms of Exterior Spans:}

The design calculations were reviewed to obtain the needed deflection data. It was found that the unfactored dead load deflection within an exterior span located at $33 \%$ of the span length $(0.33 \mathrm{~L})$ from the abutment is L/650. Per Article 3.3.2, when the unfactored dead load deflection is less than $\mathrm{L} / 500$ at $30 \%$ of the span length $(0.3 \mathrm{~L})$ from the abutment:

1. Two intermediate diaphragms shall be used.

2. The first diaphragm shall be placed between $0.3 \mathrm{~L}$ and $0.4 \mathrm{~L}$, where $\mathrm{L}$ is the length of the exterior span of interest.

3. The second diaphragm shall be located symmetrically within the same span. 
Number and Location of the Diaphragms of Interior Spans:

Per Article 3.3.2, regardless of the number of diaphragms used in the exterior spans, only two intermediate diaphragms are needed within interior spans; therefore, for the interior span:

1. Two intermediate diaphragms shall be used.

2. Each diaphragm shall be placed as close as practical to the third points of the span.

\section{B.3.3 Local Bottom Flange Buckling in the Negative Moment Region (Article 3.4)}

The maximum demand/capacity ratio in the negative moment region shall not be greater than 0.7 under the Strength I load combination in the region between $0.2 \mathrm{~L}$ and $0.3 \mathrm{~L}$ away from a pier in the unfaulted state. This requirement applies to both girders in each span.

The demand/capacity ratios for the Strength I limit state were obtained from the design calculations and are summarized for the interior and exterior girders in each span in Tables B.2 through B.7. As seen in the tables, the demand/capacity ratios were less than 0.7 in span 1 as shown in Table B.2 and Table B.4 (i.e., between 0.2L and 0.3L from the piers and shown in bold text). Hence, bottom flange buckling is not a concern in Span 1 and Span 3.

However, as shown in Table B.3, the negative moment demand/capacity ratio in span 2 near pier 2 of 0.77 exceeds the allowable limit of 0.7 . Hence, it is required to shift the bottom flange splice further from the pier such that the demand/capacity ratio falls below 0.7. Though not shown, for this bridge, it was found that shifting the splice from $0.21 \mathrm{~L}$ to $0.25 \mathrm{~L}$ from pier two into span 2 will satisfy this requirement. 
Table B.2 Demand/capacity ratios for the interior girder in the first span

\begin{tabular}{|l|c|c|c|c|c|}
\hline $\begin{array}{l}\text { Distance } \\
\text { from Pier 1 }\end{array}$ & Location (ft.) & $\begin{array}{c}\text { Strength I } \\
\text { Demand (ksi) }\end{array}$ & Capacity (ksi) & D/C & Less Than 0.7 \\
\hline $\mathbf{0 . 3 L}$ & $\mathbf{7 1 . 8}$ & - & $\mathbf{- 1 6 . 6}$ & - & $\boldsymbol{Y}$ \\
\hline & $\mathbf{7 6 . 9}$ & - & $\mathbf{- 1 6 . 6}$ & - & $\boldsymbol{Y}$ \\
\hline & Bot. Flg. Spl. & $\mathbf{- 4 . 5}$ & $\mathbf{- 1 6 . 6}$ & $\mathbf{0 . 2 7}$ & $\boldsymbol{Y}$ \\
\hline & Bot. Flg. Spl. & $\mathbf{- 3 . 7}$ & $\mathbf{- 2 9 . 6}$ & $\mathbf{0 . 1 3}$ & $\boldsymbol{Y}$ \\
\hline $\mathbf{0 . 2 L}$ & $\mathbf{8 2 . 1}$ & $\mathbf{- 4 . 6}$ & $\mathbf{- 3 0 . 2}$ & $\mathbf{0 . 1 5}$ & $\boldsymbol{Y}$ \\
\hline & 87.2 & -8.6 & -30.2 & 0.28 & - \\
\hline & Bot. Flg. Spl. & -13.5 & -30.2 & 0.45 & - \\
\hline & Bot. Flg. Spl. & -13.5 & -30.2 & 0.45 & - \\
\hline $0.1 \mathrm{~L}$ & 92.3 & -13.8 & -30.2 & 0.46 & - \\
\hline & 97.4 & -19.9 & -30.2 & 0.66 & - \\
\hline Pier 1 & 102.6 & -27.0 & -30.2 & 0.89 & - \\
\hline
\end{tabular}

Table B.3 Demand/capacity ratios for the interior girder in the second span

\begin{tabular}{|c|c|c|c|c|c|}
\hline $\begin{array}{l}\text { Distance } \\
\text { from Pier }\end{array}$ & Location (ft.) & $\begin{array}{c}\text { Strength I } \\
\text { Demand (ksi) }\end{array}$ & Capacity (ksi) & $\mathrm{D} / \mathrm{C}$ & Less Than 0.7 \\
\hline \multicolumn{6}{|c|}{ FROM PIER 1 INTO SPAN 2} \\
\hline \multirow[t]{2}{*}{ Pier 1} & 102.6 & -27.0 & -30.2 & 0.89 & - \\
\hline & 107.7 & -20.9 & -30.2 & 0.69 & - \\
\hline \multirow[t]{2}{*}{$0.1 \mathrm{~L}$} & 112.8 & -15.9 & -30.2 & 0.53 & - \\
\hline & 117.9 & -12.1 & -30.2 & 0.40 & - \\
\hline \multirow[t]{4}{*}{$0.2 L$} & 123.0 & -9.1 & -30.2 & 0.30 & $Y$ \\
\hline & Bot. Flg. Spl. & -8.8 & -30.2 & 0.29 & $Y$ \\
\hline & Bot. Flg. Spl. & -10.7 & -17.0 & 0.63 & $Y$ \\
\hline & 128.1 & -8.3 & -17.0 & 0.49 & $\boldsymbol{Y}$ \\
\hline $0.3 L$ & 133.2 & - & -17.0 & - & $\boldsymbol{Y}$ \\
\hline \multicolumn{6}{|c|}{ FROM PIER 2 INTO SPAN 2} \\
\hline \multirow[t]{4}{*}{$0.3 L$} & 174.1 & -7.6 & -17.0 & 0.45 & $\boldsymbol{Y}$ \\
\hline & 179.2 & -10.4 & -17.0 & 0.61 & $Y$ \\
\hline & Bot. Flg. Spl. & -13.1 & -17.0 & 0.77 & $N$ \\
\hline & Bot. Flg. Spl. & -9.9 & -36.4 & 0.27 & $Y$ \\
\hline \multirow[t]{2}{*}{$0.2 L$} & 184.3 & -10.2 & -36.4 & 0.28 & $Y$ \\
\hline & 189.4 & -13.2 & -36.4 & 0.36 & - \\
\hline \multirow[t]{2}{*}{$0.1 \mathrm{~L}$} & 194.5 & -16.9 & -36.4 & 0.46 & - \\
\hline & 199.6 & -21.7 & -36.4 & 0.60 & - \\
\hline Pier 2 & 204.7 & -27.6 & -36.3 & 0.76 & - \\
\hline
\end{tabular}


Table B.4 Demand/capacity ratios for the interior girder in the third span

\begin{tabular}{|l|c|c|c|c|c|}
\hline $\begin{array}{l}\text { Distance } \\
\text { from Pier 2 }\end{array}$ & Location (ft.) & $\begin{array}{c}\text { Strength I } \\
\text { Demand (ksi) }\end{array}$ & Capacity (ksi) & D/C & Less Than 0.7 \\
\hline Pier 2 & 204.7 & -27.6 & -36.3 & 0.76 & - \\
\hline & 210.2 & -20.3 & -36.3 & 0.56 & - \\
\hline $0.1 \mathrm{~L}$ & 215.6 & -14.0 & -36.3 & 0.39 & - \\
\hline & Bot. Flg. Spl. & -11.5 & -36.3 & 0.32 & - \\
\hline & Bot. Flg. Spl. & -11.5 & -36.3 & 0.32 & - \\
\hline & 221.1 & -8.6 & -36.3 & 0.24 & - \\
\hline $\mathbf{0 . 2 L}$ & $\mathbf{2 2 6 . 6}$ & -4.9 & -36.3 & $\mathbf{0 . 1 3}$ & $\boldsymbol{Y}$ \\
\hline & Bot. Flg. Spl. & -4.3 & -36.3 & $\mathbf{0 . 1 2}$ & $\boldsymbol{Y}$ \\
\hline & Bot. Flg. Spl. & -4.8 & -16.5 & $\mathbf{0 . 2 9}$ & $\boldsymbol{Y}$ \\
\hline & $\mathbf{2 3 2 . 1}$ & - & -16.5 & - & $\boldsymbol{- 1 6 . 5}$ \\
\hline $\mathbf{0 . 3 L}$ & $\mathbf{2 3 7 . 5}$ & - & - & \\
\hline
\end{tabular}


Table B.5 Demand/capacity ratios for the exterior girder in the first span

\begin{tabular}{|l|c|c|c|c|c|}
\hline $\begin{array}{l}\text { Distance } \\
\text { from Pier 1 }\end{array}$ & Location (ft.) & $\begin{array}{c}\text { Strength I } \\
\text { Demand (ksi) }\end{array}$ & Capacity (ksi) & D/C & Less Than 0.7 \\
\hline $\mathbf{0 . 3 L}$ & $\mathbf{7 7 . 2}$ & - & $\mathbf{- 1 6 . 5}$ & - & $\boldsymbol{Y}$ \\
\hline & $\mathbf{8 2 . 7}$ & - & $\mathbf{- 1 6 . 5}$ & - & $\boldsymbol{Y}$ \\
\hline & Bot. Flg. Spl. & $\mathbf{- 6 . 9}$ & $\mathbf{- 1 6 . 5}$ & $\mathbf{0 . 2 7}$ & $\boldsymbol{Y}$ \\
\hline & Bot. Flg. Spl. & $\mathbf{- 5 . 2}$ & $\mathbf{- 3 6 . 3}$ & $\mathbf{0 . 1 3}$ & $\boldsymbol{Y}$ \\
\hline $\mathbf{0 . 2 L}$ & $\mathbf{8 8 . 2}$ & $\mathbf{- 5 . 7}$ & $\mathbf{- 3 6 . 3}$ & $\mathbf{0 . 1 5}$ & $\boldsymbol{Y}$ \\
\hline & 93.8 & -10.6 & -36.3 & 0.28 & - \\
\hline & Bot. Flg. Spl. & -16.1 & -36.3 & 0.45 & - \\
\hline & Bot. Flg. Spl. & -16.1 & -36.3 & 0.45 & - \\
\hline $0.1 \mathrm{~L}$ & 99.3 & -16.4 & -36.3 & 0.46 & - \\
\hline & 104.8 & -23.1 & -36.3 & 0.66 & - \\
\hline Pier 1 & 110.3 & -30.7 & -36.3 & 0.85 & - \\
\hline
\end{tabular}

Table B.6 Demand/capacity ratios for the exterior girder in the second span

\begin{tabular}{|c|c|c|c|c|c|}
\hline $\begin{array}{l}\text { Distance } \\
\text { from Pier }\end{array}$ & Location (ft.) & $\begin{array}{c}\text { Strength I } \\
\text { Demand (ksi) }\end{array}$ & Capacity (ksi) & $\mathrm{D} / \mathrm{C}$ & Less Than 0.7 \\
\hline \multicolumn{6}{|c|}{ FROM PIER 1 INTO SPAN 2} \\
\hline \multirow[t]{2}{*}{ Pier 1} & 110.3 & -30.7 & -36.3 & 0.85 & - \\
\hline & 115.8 & -23.9 & -36.3 & 0.66 & - \\
\hline \multirow[t]{2}{*}{$0.1 \mathrm{~L}$} & 121.3 & -18.3 & -36.3 & 0.50 & - \\
\hline & 126.8 & -14.1 & -36.3 & 0.39 & - \\
\hline \multirow[t]{4}{*}{$0.2 L$} & 132.3 & -10.7 & -36.3 & 0.29 & $\boldsymbol{Y}$ \\
\hline & Bot. Flg. Spl. & -10.3 & -36.3 & 0.28 & $\boldsymbol{Y}$ \\
\hline & Bot. Flg. Spl. & -12.5 & -23.2 & 0.54 & $Y$ \\
\hline & 137.7 & -10.0 & -23.2 & 0.43 & $\boldsymbol{Y}$ \\
\hline $0.3 L$ & 143.2 & - & -23.2 & - & $\boldsymbol{Y}$ \\
\hline \multicolumn{6}{|c|}{ FROM PIER 2 INTO SPAN 2} \\
\hline \multirow[t]{4}{*}{$0.3 L$} & 187.2 & -10.0 & -23.2 & 0.43 & $\boldsymbol{Y}$ \\
\hline & 192.6 & -13.1 & -23.2 & 0.56 & $Y$ \\
\hline & Bot. Flg. Spl. & -16.1 & -23.2 & 0.69 & $Y$ \\
\hline & Bot. Flg. Spl. & -12.1 & -39.2 & 0.31 & $Y$ \\
\hline \multirow[t]{2}{*}{$0.2 L$} & 198.1 & -12.4 & -39.2 & 0.32 & $Y$ \\
\hline & 203.6 & -15.8 & -39.2 & 0.40 & - \\
\hline \multirow[t]{2}{*}{$0.1 \mathrm{~L}$} & 209.1 & -19.9 & -39.2 & 0.51 & - \\
\hline & 214.6 & -25.3 & -39.2 & 0.65 & - \\
\hline Pier 2 & 220.1 & -31.9 & -39.2 & 0.81 & - \\
\hline
\end{tabular}


Table B.7 Demand/capacity ratios for the exterior girder in the third span

\begin{tabular}{|l|c|c|c|c|c|}
\hline $\begin{array}{l}\text { Distance } \\
\text { from Pier 2 }\end{array}$ & Location (ft.) & $\begin{array}{c}\text { Strength I } \\
\text { Demand (ksi) }\end{array}$ & Capacity (ksi) & D/C & Less Than 0.7 \\
\hline Pier 2 & 220.1 & -31.9 & -39.2 & 0.81 & - \\
\hline & 226.0 & -24.1 & -39.2 & 0.61 & - \\
\hline $0.1 \mathrm{~L}$ & 231.9 & -17.2 & -39.2 & 0.44 & - \\
\hline & Bot. Flg. Spl. & -14.5 & -39.2 & 0.37 & - \\
\hline & Bot. Flg. Spl. & -14.5 & -39.2 & 0.37 & - \\
\hline & 237.8 & -11.3 & -39.2 & 0.29 & - \\
\hline $\mathbf{0 . 2 L}$ & $\mathbf{2 4 3 . 6}$ & $\mathbf{- 6 . 2}$ & $\mathbf{- 3 9 . 2}$ & $\mathbf{0 . 1 6}$ & $\boldsymbol{Y}$ \\
\hline & Bot. Flg. Spl. & $\mathbf{- 5 . 5}$ & $\mathbf{- 3 9 . 2}$ & $\mathbf{0 . 1 4}$ & $\boldsymbol{Y}$ \\
\hline & Bot. Flg. Spl. & $\mathbf{- 8 . 2}$ & $\mathbf{- 1 7 . 0}$ & $\mathbf{0 . 4 8}$ & $\boldsymbol{Y}$ \\
\hline & $\mathbf{2 4 9 . 5}$ & - & $\mathbf{- 1 7 . 0}$ & - & $\boldsymbol{Y}$ \\
\hline $\mathbf{0 . 3 L}$ & $\mathbf{2 5 5 . 4}$ & - & $\mathbf{- 1 7 . 0}$ & - & \\
\hline
\end{tabular}

\section{B.3.4 Flexural Yielding in Positives Moment Region of Flanges in Intact Girder Design Details}

The maximum demand/capacity ratio in the positive moment region of each span shall not be greater than 0.8 under the Strength I load combination in the unfaulted state. This requirement applies to both girders in each span.

The demand/capacity ratios for the Strength I limit state were obtained from the design calculations and are summarized for the interior and exterior girders in each span in Tables B.8 and B.9. As seen in the tables, the demand/capacity ratios were always less than 0.8 . Hence, excessive positive moment inelastic behavior in the faulted state is not a concern. (It is noted that data for span 2 are not presented as the demand/capacity ratios were all less than 0.3 for Strength I positive moment. Hence, span 2 also satisfies this requirement.) 
Table B.8 Demand/capacity ratios for the interior girder

\begin{tabular}{|c|c|c|c|c|c|}
\hline $\begin{array}{l}\text { Tenth } \\
\text { Point }\end{array}$ & Location (ft.) & $\begin{array}{c}\text { Strength I } \\
\text { Demand (kips-ft) }\end{array}$ & $\begin{array}{l}\text { Capacity } \\
\text { (kips-ft) }\end{array}$ & $\mathrm{D} / \mathrm{C}$ & Less Than 0.8 \\
\hline 0 & 0.0 & 25 & 17154 & 0.00 & $Y$ \\
\hline 1 & 10.3 & 3959 & 17179 & 0.23 & $Y$ \\
\hline 2 & 20.5 & 6511 & 17075 & 0.38 & $\bar{Y}$ \\
\hline 3 & 30.8 & 8073 & 17032 & 0.47 & $Y$ \\
\hline 4 & 41.0 & 8716 & 17061 & 0.51 & $Y$ \\
\hline 5 & 51.3 & 8589 & 17172 & 0.50 & $Y$ \\
\hline 6 & 61.5 & 7322 & 17288 & 0.42 & $Y$ \\
\hline 7 & 71.8 & 4985 & 17534 & 0.28 & $Y$ \\
\hline \multicolumn{6}{|c|}{ ALL POSITIVE MOMENT D/C RATIOS $<0.3$ FOR SPAN 2} \\
\hline 23 & 237.5 & 5472 & 17596 & 0.31 & $\boldsymbol{Y}$ \\
\hline 24 & 248.5 & 7824 & 17235 & 0.45 & $\boldsymbol{Y}$ \\
\hline 25 & 259.4 & 9213 & 17098 & 0.54 & $\boldsymbol{Y}$ \\
\hline 26 & 270.4 & 9535 & 17015 & 0.56 & $\boldsymbol{Y}$ \\
\hline 27 & 281.3 & 9061 & 17034 & 0.53 & $\boldsymbol{Y}$ \\
\hline 28 & 292.3 & 7226 & 17048 & 0.42 & $Y$ \\
\hline 29 & 303.2 & 4181 & 17043 & 0.25 & $Y$ \\
\hline 30 & 314.2 & 28 & 17010 & 0.00 & $Y$ \\
\hline
\end{tabular}

Table B.9 Demand/capacity ratios for the exterior girder

\begin{tabular}{|c|c|c|c|c|c|}
\hline $\begin{array}{l}\text { Tenth } \\
\text { Point }\end{array}$ & Location (ft.) & $\begin{array}{c}\text { Strength I } \\
\text { Demand (kips-ft) }\end{array}$ & $\begin{array}{l}\text { Capacity } \\
\text { (kips-ft) }\end{array}$ & $\mathrm{D} / \mathrm{C}$ & Less Than 0.8 \\
\hline 0 & 0.0 & 38 & 17318 & 0.00 & $Y$ \\
\hline 1 & 11.0 & 4633 & 17335 & 0.27 & $Y$ \\
\hline 2 & 22.1 & 7561 & 17250 & 0.44 & $Y$ \\
\hline 3 & 33.1 & 9295 & 17230 & 0.54 & $\bar{Y}$ \\
\hline 4 & 44.1 & 9985 & 17241 & 0.58 & $Y$ \\
\hline 5 & 55.2 & 9810 & 17330 & 0.57 & $Y$ \\
\hline 6 & 66.2 & 8264 & 17436 & 0.47 & $Y$ \\
\hline 7 & 77.2 & 5524 & 17697 & 0.31 & $Y$ \\
\hline \multicolumn{6}{|c|}{ ALL POSITIVE MOMENT D/C RATIOS $<0.3$ FOR SPAN 2} \\
\hline 23 & 255.4 & 5841 & 17756 & 0.33 & $\boldsymbol{Y}$ \\
\hline 24 & 267.2 & 8760 & 17383 & 0.50 & $\boldsymbol{Y}$ \\
\hline 25 & 278.9 & 10405 & 17245 & 0.60 & $\boldsymbol{Y}$ \\
\hline 26 & 290.7 & 10926 & 17204 & 0.64 & $\boldsymbol{Y}$ \\
\hline 27 & 302.5 & 10392 & 17228 & 0.60 & $\boldsymbol{Y}$ \\
\hline 28 & 314.3 & 8362 & 17220 & 0.49 & $Y$ \\
\hline 29 & 326.0 & 4866 & 17198 & 0.28 & $Y$ \\
\hline 30 & 337.8 & 45 & 17173 & 0.00 & $Y$ \\
\hline
\end{tabular}




\section{Summary}

The proposed specifications have been used to evaluate the twin tub girder bridge in this example. Since all of the requirements have been met, the bridge need not be classified has having FCMs

but instead, SRMs. The bridge shall still be fabricated to Clause 12 of the AASHTO/AWS D1.5 Bridge Welding Code Using Grades Meeting the Fracture Critical Tension Component Impact Test Requirements of ASTM A709. 


\section{S-BRITE Center}

As infrastructure continues to age, the engineers who designed and had first-hand knowledge of the then new structures (e.g., the Interstate era) eventually exit the workforce. Further, the vast majority of the infrastructure comprises structures built with older materials, design philosophies, and construction practices that are no longer discussed in the classroom. To successfully maintain the existing steel bridge inventory, expertise is needed in the areas of deterioration, fatigue, fracture, corrosion, repair/ retrofit, coatings, materials, NDE, riveting, welding, and fabrication. Using Purdue's existing strengths in education and research, the Steel Bridge Research, Inspection, Training, and Engineering (S-BRITE) Center fills a growing need in the transportation industry as it relates to existing and aging steel bridges.

Additional information about the S-BRITE Center is available at https://engineering.purdue.edu /CAI/SBRITE.

\section{Publication}

This report was published by the S-BRITE Center at Purdue University. The full content of this technical report (in pdf and e-book formats) is available for download at https:// doi.org/10.5703/1288284317106.

\section{Open Access and Collaboration with Purdue University}

The Indiana legislature established the Joint Highway Research Project in 1937. In 1997, this collaborative venture between the Indiana Department of Transportation and Purdue University was renamed as the Joint Transportation Research Program (JTRP) to reflect state and national efforts to integrate the management and operation of various transportation modes. Since 1937, the JTRP program has published more than 1,600 technical reports. In 2010, the JTRP partnered with the Purdue University Libraries to incorporate these technical reports in the University's open access digital repository and to develop production processes for rapidly disseminating new research reports via this repository. Affiliated publications have since been added to the JTRP collection, which has exceeded 1.8 million downloads. 